\title{
The Impact of technology and demand shocks on structural dynamics: evidence from Austrian manufacturing
}

Citation for published version (APA):

Holzl, W., \& Reinstaller, A. (2004). The Impact of technology and demand shocks on structural dynamics: evidence from Austrian manufacturing. MERIT, Maastricht Economic Research Institute on Innovation and Technology. MERIT-Infonomics Research Memorandum Series No. 015 https://doi.org/10.26481/umamer.2004015

Document status and date:

Published: 01/01/2004

DOI:

10.26481/umamer.2004015

Document Version:

Publisher's PDF, also known as Version of record

\section{Please check the document version of this publication:}

- A submitted manuscript is the version of the article upon submission and before peer-review. There can be important differences between the submitted version and the official published version of record. People interested in the research are advised to contact the author for the final version of the publication, or visit the DOI to the publisher's website.

- The final author version and the galley proof are versions of the publication after peer review.

- The final published version features the final layout of the paper including the volume, issue and page numbers.

Link to publication

\footnotetext{
General rights rights.

- You may freely distribute the URL identifying the publication in the public portal. please follow below link for the End User Agreement:

www.umlib.nl/taverne-license

Take down policy

If you believe that this document breaches copyright please contact us at:

repository@maastrichtuniversity.nl

providing details and we will investigate your claim.
}

Copyright and moral rights for the publications made accessible in the public portal are retained by the authors and/or other copyright owners and it is a condition of accessing publications that users recognise and abide by the legal requirements associated with these

- Users may download and print one copy of any publication from the public portal for the purpose of private study or research.

- You may not further distribute the material or use it for any profit-making activity or commercial gain

If the publication is distributed under the terms of Article $25 \mathrm{fa}$ of the Dutch Copyright Act, indicated by the "Taverne" license above, 
MERIT-Infonomics Research Memorandum series

The Impact of technology and demand shocks on structural dynamics: evidence from Austrian manufacturing

Werner Hölzl and Andreas Reinstaller

2004-015

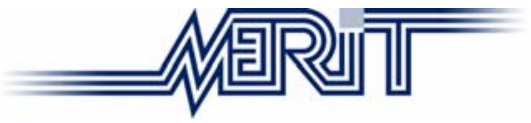

MERIT - Maastricht Economic Research Institute on Innovation and Technology

PO Box 616

6200 MD Maastricht

The Netherlands

T: +31433883875

F: +31433884905

http://www.merit.unimaas.nl

e-mail:secr-merit@merit.unimaas.nl

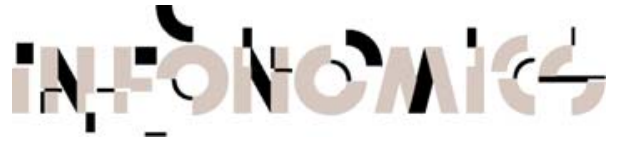

International Institute of Infonomics

c/o Maastricht University

PO Box 616

6200 MD Maastricht

The Netherlands

T: +31 433883875

F: +31 453884905

http://www.infonomics.nl e-mail: secr@infonomics.nl 


\title{
The impact of technology and demand shocks on structural dynamics: evidence from Austrian manufacturing
}

\author{
Werner Hölzl and Andreas Reinstaller
}

July 19, 2004

\begin{abstract}
This paper examines the link between structural change between and within industries. We analyse the influence of sector specific developments in productivity and demand on net entry and employment in 19 industrial sectors of the Austrian economy. Based on the model of structural dynamics of Pasinetti, we develop an identification scheme that allows us to extract technology and demand shocks, by means of a structural vector autoregressive (SVAR) model with long-run restrictions. We study the patterns of productivity and demand shocks across industries by means of a principal components analysis and find that sectoral and macro-economic developments in demand strongly correlate, while this is not the case for technology shocks. Impulse-response analysis shows that for almost all sectors productivity growth rates experience an immediate increase to positive technology shocks while the hours worked decline as conjectured by Pasinetti. Finally, we use the identified shocks as explanatory variables in time-series cross section regressions on net-entry and employment data. Both types of shocks are able to explain dynamics on the industry level in terms of employment and sales but not firm dynamics.
\end{abstract}

Address:

Vienna University of Economics and Business Administration, Department of Economics, Augasse 2-6, 1090 Vienna, Austria,

E-mail: Werner.Hoelzl@wu-wien.ac.at (Hölzl), areinst@wu.edu (Reinstaller).

JEL Codes: D24, L16, O30 


\section{Introduction}

There are two different literatures which deal with structural dynamics. The first is concerned with structural change, which analyses the dynamics between industries and the changing importance of specific sectors within the economy (or the manufacturing sector) as a whole is analysed. Here differences in income elasticities of demand for the output of a sector and productivity differentials are the drivers of structural shifts in the economy. The contrasting development of demand elasticities and productivity are reflected in the evolution of sectoral employment rates. This research tradition is exemplified by the contributions of Pasinetti ( [29] and [30]). The second and in recent years more prominent approach is concerned with the evolution and structural change within industries. In this research area employment and productivity developments reflect competition at the industry level. In Schumpeterian contributions this is a process of selection of best practice, which is achieved through innovation and imitation in the market leading to entry and exit of firms. It depends on underlying technological regimes (e.g. Nelson and Winter [21], Winter [36] or Metcalfe [24]). In the related industry life-cycle literature authors have stressed that patterns of sectoral structural change evolve around a radical innovation, which ensures high growth in sales at first. As technological opportunity vanishes over time the industry reaches a stage of maturity and eventually declines (see e.g. Klepper [20]). Over the life-cycle the introduction of new technologies may cause firm shake-outs and hence changes in the patterns of productivity and employment (see Jovanovic and MacDonald [19]).

Recent contributions have tried to link these two strands of the literature (see Andersen [2], Montobbio [27], Metcalfe et al. [25] or Peneder [32]), and tried to show that sectoral dynamics and unbalanced growth in the economy are interrelated. Montobbio identifies two mechanisms linking inter-industry and intra-industry dynamics, called sorting and selection. Sorting is based on the idea that the industrial composition of demand varies as income grows. This captures essentially Pasinetti's assumption that consumer preferences developing according to Engel's law have an impact on the relativ growth patterns of sectors in an economy. Selection in turn reflects price competition within sectors, but also between sectors producing substitutes. Firms or sectors which are able to produce at lower cost will gain more consumers and grow faster. In Montobbio's own words "structural change [...] is a process which starts at the micro-level and is the outcome of competition and selection within sectors and competition, selection and sorting among firms in different sectors", [27, p.408]. This suggests that changes in sectoral rates of productivity and demand growth should be correlated to changes in industrial demography at the micro-level. In this paper, we will explore this link. 
The paper has two main aims. The first is to devise a method to identify technology and demand shocks in aggregate industry data. Solow residuals have been used to represent sectoral technology shocks (see Burnside et al [6] or Harberger [17]). However, they are based on Neoclassical production theory and are not unproblematic, as the empirical and theoretical relevance of the residuals (see Carlaw and Lipsey [7] or Felipe and Fisher [11]) is thought to be controversial. To sum up, total factor productivity is a fuzzy and problematic measure for technical advance. Therefore we use a structural VAR method with long-run restrictions using series on labour productivity and hours worked to extract technology and demand shocks. This technique figures prominently in business cycle research (Galí [13], [14] or Francis and Ramey [12]), but we show that it can be identified quite naturally through Pasinetti's [30] model of structural change. We apply this method to nineteen manufacturing sectors in the Austrian economy. This allows us to pursue the second aim of this paper, which is to examine how these shocks impact on the structural dynamics in each single sector in terms of employment growth and the market structure.

The paper is structured as follows. In section two we derive the identification scheme for the SVAR model with long-run restrictions. In section three the empirical model is specified. In section four we discuss briefly the data sources used in our econometric study. In section five we present the results from the SVAR analysis and use the identified shocks in time-seriescross-section regressions on entry, exit and net entry in the different sectors. Section six concludes this paper with a discussion of our results.

\section{Sectoral dynamics and changes in em- ployment induced by technology and demand shocks}

Pasinetti's [30] model is a natural starting point for the analysis of structural economic dynamics and employment. In his book he describes the factors underlying the changing composition of output and structural evolution of the production system in capitalistic economies. This process is based on two main assumptions. The first is that there is a trend for productivity to increase in the long run at rates that are specific to each sector. The second assumption is that Engel's law in consumption leads to the rise or decline of demand for products of specific sectors depending on whether the commodities they produce are superior or inferior goods. Together these factors shape the structure of an economy.

Productivity in sector $i$ at any time $t$ is reflected in the labour coefficients given by the following expression 


$$
l_{i}(t)=l_{i}(t-\theta) \mathrm{e}^{-\rho_{i}(t) \theta} .
$$

The labour coefficients $l_{i}$ are here interpreted as the hours per worker needed to produce one unit of output in sector $i$ over a period $\theta$. The parameter $\rho_{i}(t)$ reflects the rate of productivity change which is constant over period $\theta$, but may change the next period. In each period the sectors can be ranked according to their coefficient $\rho_{i}(\mathrm{t})$.

The second equation is per-capita consumption in terms of physical output of each sector $i$. Demand changes at a rate $r_{i}(t)$ that is different from the rate of productivity change. This rate changes over time as well in dependence of Engel's law,

$$
c_{i}(t)=c_{i}(t-\theta) \mathrm{e}^{r_{i}(t) \theta} .
$$

Given these two laws of motion the prices and physical outputs in each sector $i$ are determined by

$$
\begin{aligned}
p_{i}(t) & =l_{i}(t-\theta) \mathrm{e}^{-\rho_{i}(t) \theta} w_{i}(t) \\
& \text { and } \\
Q_{i}(t) & =c_{i}(t-\theta) N(t-\theta) \mathrm{e}^{\left(g+r_{i}(t)\right) \theta}
\end{aligned}
$$

where $w_{i}(t)$ represent the average unit cost in sector $i$ and $N(t)$ represents the total population in the economy growing at an exogenous and constant rate $g .{ }^{1}$

The dynamics of employment captures much of the evolutionary forces underlying structural change. Full-employment is determined by both, productivity growth and the change of the sectoral per capita consumption coefficients. While the factors influencing technical change are largely seen to be autonomous, demand is the ultimate selection mechanism as it enforces technical designs or techniques of production that have economic value. Together technical change and demand development shape the structure of an economy.

In order to examine the dynamics of employment induced by Pasinetti's laws of motion, we look at the total amount of hours worked in each sector during a time span $\theta$, which for each sector is given $i$ by

$$
h_{i}(t+\theta)=l_{i}(t) c_{i}(t) N(t) \mathrm{e}^{\left[g+r_{i}(t+\theta)-\rho_{i}(t+\theta)\right] \theta},
$$

i.e., the total output $c_{i}(t) N(t)$ times the sectoral labour coefficient. Given this relationship, the long-run pattern of change in worked hours and employment depends on both changes in productivity and changes in demand. ${ }^{2}$

\footnotetext{
${ }^{1}$ In his book Pasinetti ignores fixed capital for the sake of clarity. For our purposes we interpret $w(t)_{i}$ as full cost.

${ }^{2}$ Pasinetti formulates his model in terms of employment. From our equation (5) the
} 
Pasinetti [30] explicitly asserts that the rates $\rho_{i}$ and $r_{i}$ are not constant over time, but only during some arbitrarily small time span $\theta$, suggesting that the rates change after innovations in technology and demand behaviour due to human learning. We follow up this assertion and examine the causes shifting these rates empirically. For this purpose we specify a simple empirical model based on equations (1) and (2), which are used to identify instantaneous shocks to the long-run growth rates in these equations.

\subsection{Technology and demand shocks}

In order to identify the factors affecting the rates of change in productivity and sectoral consumption coefficients, we will assume that $\rho_{i}(t)$ and $r_{i}(t)$ change through stochastic shocks and follow a random walk with drift. We define $\rho_{i}(t)$ as the sum of past stochastic technology shocks, a current shock $\sigma_{i, t}$, and a drift variable $\zeta_{s, i}$, which captures the technological opportunity shaping the overall growth pattern in a sector $i$, i.e.

$$
\rho_{i}(t)=\zeta_{s, i}+\rho_{i}(t-1)+\sigma_{s_{i}, t},
$$

where $\sigma_{s_{i}, t} \sim$ i.i.d $\left(0, D_{\sigma_{s}}\right)$. Successive substitution yields

$$
\rho_{i}(t)=\zeta_{s, i} t+\rho_{i}\left(t_{0}\right)+\sum_{\tau=0}^{t-1} \sigma_{s_{i}, t-\tau},
$$

which reflects the assumption of a deterministic and a stochastic component in the development of the rate of change in productivity. The parameter $\rho_{i}\left(t_{0}\right)$ gives the initial value of the rate of growth at some time $t_{0}$. Accordingly the expected value $E\left[\sum_{k=0}^{t-1} \sigma_{s_{i}, t-\tau}\right]$ is zero such that $E\left[\rho_{i}(t)\right]=\zeta_{s, i} t+\rho_{i}\left(t_{0}\right)$. Similarly, for the rate of change in demand we write

$$
r_{i}(t)=\zeta_{d, i}+r_{i}(t-1)+\sigma_{d_{i}, \tau},
$$

and get the term

$$
r_{i}(t)=\zeta_{d, i} t+r_{i}\left(t_{0}\right)+\sum_{\tau=0}^{t-1} \sigma_{d_{i}, t-\tau}
$$

again through successive substitution. As before $\sigma_{d_{i}, t}$ is the current shock affecting the rate of change of the sectoral consumption coefficient and $\zeta_{d, i}$ reflects the general market opportunity underlying the output of sector $i$. The shock is again a random variable $\sigma_{s_{i}, t} \sim$ i.i.d $\left(0, D_{\sigma_{d}}\right)$ such that $E\left[\sum_{\tau=0}^{t-1} \sigma_{d_{i}, t-\tau}\right]=0$ and $E\left[r_{i}(t)\right]=\zeta_{d, i} t+r_{i}\left(t_{0}\right)$. Taken together, the parameters $\zeta$ may be interpreted as the technological and market opportunity in the sector, determining the drift of the random process according to which the growth rates of demand and technology evolve.

level of employment in each sector can be obtained. If $\omega$ represents the amount of hours a worked by one worker, then employment in each sector is equal to $e_{i}(t)=\frac{h_{i}(t)}{\omega}$. 
The change of $\rho_{i}$ and $r_{i}$ between to periods $t$ and $t-1$ isolates the instantaneous effect of shocks in each period on the long-run growth rate. This is what we are interested in. Unlike in the original equations (1), (2), (3) and (4) we set the parameter $\theta=1$. Then, given the definition of $\rho_{i}$ we have $\Delta \rho_{i}(t)=\rho_{i}(t)-\rho_{i}(t-1)$ which is

$$
\Delta \rho_{i}(t)=\zeta_{s, i}+\sigma_{s_{i}, t}
$$

In an analogous way we obtain the shock on the sectoral demand coefficient

$$
\Delta r_{i}(t)=\zeta_{d, i}+\sigma_{d_{i}, t}
$$

This means that the any observed change in $\rho_{i}$ or $r_{i}$ during a any time period as a realization the deterministic trend and a deviation from it through a stochastic shock. These terms are the stochastic equivalents of the deterministic exponents in Pasinetti's original equations (1) and (2), which now turn into

$$
\begin{aligned}
& \tilde{l}_{i}(t)=\tilde{l}_{i}(t-1) \mathrm{e}^{-\Delta \rho_{i}(t)} \\
& \tilde{c}_{i}(t)=\tilde{c}_{i}(t-1) \mathrm{e}^{\Delta r_{i}(t)}
\end{aligned}
$$

The stochastic equation for the development of hours over time as specified in equation (5), is easily derived from the results in (10):

$$
\tilde{h}_{i}(t)=\tilde{h}_{i}(t-1) \mathrm{e}^{g+\Delta r_{i}(t)-\Delta \rho_{i}(t)},
$$

where $\tilde{h}_{i}(t) \equiv \tilde{l}_{i}(t) \tilde{c}_{i}(t) N(t)$. Positive demand shocks will tend to increase the amount of hours worked in a sector, while positive productivity shocks will lower them. In line with Pasinetti's model, hours and employment fall with increasing productivity and they grow with increasing demand.

Knowing productivity shocks and hours worked it is thus possible to identify demand shocks, which we are interested in. Taking logs of equations (10) and (11) we get

$$
\begin{aligned}
\Delta \hat{l}_{i}(t) & \equiv \ln \left[\tilde{l}_{i}(t)\right]-\ln \left[\tilde{l}_{i}(t-1)\right]=-\Delta \rho_{i}(t) \\
\Delta \hat{h}_{i}(t) & \equiv \ln \left[\tilde{h}_{i}(t)\right]-\ln \left[\tilde{h}_{i}(t-1)\right]=-\Delta \rho_{i}(t)+\Delta r_{i}(t)
\end{aligned}
$$

which together form the basis of the identification scheme for the structural VAR model in the next section. Please, note that equation (13) neglects population growth as it is an exogenous parameter common to all sectors and hence will not explain much of the changes between sectors.

Cross effects Equation (13) shows that there exist cross effects between technological development and demand. It should be noted first that the model is specified in terms of long run effects. Therefore its specification reflects the assumption that changes in demand have no permanent impact 
on the development of labour productivity. From the point of view of the literature on technical change this is plausible. Technological advances are able to lead to the creation of new or foster the growth of established markets. Increases in productivity increase the real income of households and therefore increase also demand. Productivity induced cost reductions may increase the number of potential users of a product, while technological innovations are able to create new markets. Hence, technical change is likely to have a beneficial and permanent effect on demand.

The absence of a cross effect between the growth of the sectoral coefficients of consumption and productivity in equation (12) needs some explanation. It has been a matter of long and intense debates whether demand affects productivity and growth in the long run. Demand has often been thought of as an important incentive mechanism for innovation (for an overview see Dosi [9]). Indeed, one may think about several propagation mechanisms on how demand shocks may have an effect on the price system and possibly also on the rate of innovation in a sector. For instance, a sequence of negative shocks to the consumption coefficients may cause the output of a sector to shrink. This in turn may induce stronger competition amongst firm in this sector for the stationary or shrinking market, which may induce a search for cost cutting potentials, increasing the efficiency of the used production technique and leading to the adoption of new process innovations. On the other hand, if the output of a sector expands - this may affect the pace of technical change in that market as well. Schmookler [33, p.208] for instance has concluded that "invention is governed by the extent of the market", and that "the belief that invention, or the production of technology generally, is in most instances a noneconomic activity, is false". Here he followed up the traditional Smithian argument, that the division of labour is governed by the extent of the market. This demand pull hypothesis of technical change has nevertheless been contested. Mowery and Rosenberg [28] for instance have argued that invention per se may be well driven by economic incentives coming from opportunity perceived through a fast expanding demand, but whether an invention becomes an innovation is quite a different issue as the process of innovation is highly erratic and innovations are successful only rarely. Mokyr [26] on the other hand asserts that it is the increase in productivity that has generated new income and therefore demand during the first industrial revolution. Hence, demand cannot pull innovation and productivity. For these reasons it is unlikely that demand induced technical change is in any way different from autonomous technical change. In our view only productivity improvements have a long run impact on economic growth, while demand innovations have only a transitory effect on productivity changes (e.g. over the business cycle). As our analysis will nevertheless show demand has the important role of sorting mechanism identified by Pasinetti and has permanent effects on 
employment in the single economic sectors we study. These considerations are reflected in equations (13) and (12).

\subsection{On the nature of changes to the rates of change in sectoral productivity and per capita consumption}

Equations (3) and (4) have one scale (cost and population) and one structural component (productivity and demand growth). The structural components drive the dynamic process, and are realized by sequences of shocks as equations (8) and (9) show. Given the multi-sectoral nature of the model the question is whether there exist common factors explaining the variation present in the technology and demand shocks of all sectors, reflecting economy wide or sector specific developments. In the empirical analysis that follows we will decompose the variation in all shock by means of a principal components analysis. For this purpose we will briefly discuss the likely nature of the components we will find in the empirical results later in this paper.

In a multi-sectoral economy correlations between technology or demand shocks may have a number of common sources. Following a classical and very useful classification [34], these may be

1. internal to some subset of firms operating in that sector and internal to the sector in the sense that they are not caused by technical change or changes in demand for goods in other sectors.

2. They may be internal to the sector but external to the firms in the presence of fast sectoral spill-overs.

3. Finally, they may be external to both, the sector and the firms operating there.

With this taxonomy in mind we will discuss the character of common components in the identified technology and demand shocks.

Technology shocks Technology shocks internal to the sector and internal to some subset of firms reflect competition within sectors as discussed in the large body of evolutionary studies on the dynamics of competition based on the seminal contributions of Nelson and Winter [21], Winter [36] or Metcalfe [24]. They mirror firm specific technological innovations affecting the competitive landscape within the sector. Such shocks are idiosyncratic and should not be observed in other sectors. They are the major source for the variety of firms on the sectoral level. Depending on the weight of the sector in the overall economy and the weight of innovating firms in sectors they should give rise to small sector specific shocks in components explaining relatively small amounts in total variation. This is also be true for shocks internal to an industry but external to the single firms as these two sources 
of shocks are likely to be difficult to distinguish in aggregate data. Industry specific externalities arising for instance if some new knowledge generated in one firm spills over to other firms, are very common and diffuse very quickly. The classical study of Mansfield [23] has shown that information concerning the detailed nature and operation of new products or processes leaks out within about twelve month. So unless the frequency of observations is not very high and disaggregated, firm specific technology shocks cannot be isolated. In both cases one should nevertheless find sector specific components in variance.

Shocks arising external to an industry can have a localized or a global effect. In the first case the related principal components should affect only a limited number of industries that are technologically or economically integrated to some degree or show similar structural characteristics (e.g. high intangible sunk costs, cumulativeness of the knowledge base etc.). Competition in one sector for instance may lead to sector specific reductions in average cost of production and the rate of change in productivity, which has then an impact on the cost structure of interrelated sectors. In the second case the components should affect a large number of industries, indicating the pervasive nature of the underlying technological development. In both cases, however, the components should explain a higher level of total variance. Finally, some components are likely to reflect some macro-economic or larger institutional factors (like existing National Innovation Systems/Policies) affecting all sectors in the economy. The components explaining these factors should explain a relatively large amount of variation as they are common to all sectors. In any case the observed heterogeneity in the sectoral technology shocks likely is to be very high, so that an interpretation of common factors may be difficult.

Demand shocks The sectoral output, on the other hand, is determined by the evolution of demand in each sector and population growth. The system of sectoral outputs reflects long run income changes on a personal and an economy wide level, short run business cycles and sector specific changes in consumer preferences. Global changes in income will affect the sectoral consumption coefficients in two ways. They should lead to a global change in consumption coefficients directly through Engel's law. While the consumption coefficients in all sectors will change in line with the global change in income, sectoral coefficients will also reflect the fact whether the goods produced there are inferior or superior. There should thus be one variance component reflecting global demand changes on one reflecting changes according to the income elasticities of the goods.

Personal income changes will at best appear as negligible micro shocks, which nevertheless become relevant if over time these changes affect many people in the consumer cohorts influencing a specific sectoral consumption 
coefficient summing up and slowly changing it. Shifts in personal income distribution may have an impact on the structure of the economy through these mechanisms. Consumer learning and changes in social norms or institutions on the other hand may induce changes in consumer preferences which find a clear reflection in the sectoral consumption coefficients. Consumers learning about the environmentally harmful consequences of production techniques employed in certain sectors, for instance, may search for substitutes and if they find them switch to these alternatives inducing a decline in the demand of the sectors using these techniques. This will be reflected in idiosyncratic shocks to the consumption coefficients of these sectors. From his short discussion appears that the consumption coefficient are of particular interest, because they reflect many social and institutional characteristics of an economy and hence determine the selection environment of firms and through this structural change in an economy.

\section{Identifying technology and demand shocks with structural VARs: the empirical model}

Equations (12) and (13) form the starting point of our empirical model based on a structural VAR approach with long run restrictions developed originally by Blanchard and Quah [4]. A central assumption justifying the long run restriction is that only log productivity $l(t)$ follows a non-stationary process and that therefore only technology shocks have a permanent effect on its the development. In other words, we assume that log labour productivity has a unit root. Demand disturbances identified through hours worked in turn will have only a temporary effect on productivity. Therefore the empirical model in this section is identical to the one devised by Galí [13], [14] in a different theoretical and a pure macro-economic context.

We think about the observed changes in log productivity $\Delta \hat{l}_{i, t}$ and in the $\log$ of worked hours $\Delta \hat{h}_{i, t}$ as determined by a $\operatorname{VMA}(\infty)$ process depending on present and past technology and demand shocks. Accordingly, for each industrial sector $i$ we define $\hat{\mathbf{y}}_{i, t}=\left[\begin{array}{c}\Delta \hat{l}_{i, t} \\ \Delta \hat{h}_{i, t}\end{array}\right]$ and write

$$
\begin{aligned}
\hat{\mathbf{y}}_{i, t} & =\boldsymbol{\Phi}_{i, 0} \sigma_{i, t}+\boldsymbol{\Phi}_{i, 1} \sigma_{i, t-1}+\boldsymbol{\Phi}_{i, 2} \sigma_{i, t-2} \ldots=\sum_{\ell=0}^{\infty} L^{\ell}\left[\begin{array}{ll}
\phi_{11_{\ell}} & \phi_{12_{\ell}} \\
\phi_{21_{\ell}} & \phi_{22_{\ell}}
\end{array}\right]\left[\begin{array}{l}
\sigma_{s_{i, t}} \\
\sigma_{d_{i, t}}
\end{array}\right] \\
& =\boldsymbol{\Phi}_{i}(L) \sigma_{i, t},
\end{aligned}
$$

where $L$ is the lag operator, the $\sigma_{i, t}=\left[\begin{array}{c}\sigma_{s_{i, t}} \\ \sigma_{d_{i, t}}\end{array}\right]$ are the vectors of technology and non-technology shocks in each period and $\boldsymbol{\Phi}_{i}(L)=\sum_{\ell=0}^{\infty} L^{\ell} \boldsymbol{\Phi}_{i, \ell}$ is the long-run multiplier matrix of these shocks. The technology and demand shocks are assumed to be orthogonal, i.e. $\sigma_{s_{i, t}} \perp \sigma_{d_{i, t}}$, and to have unit variance, $E\left[\sigma_{i, t} \sigma_{i, t}^{\prime}\right]=\mathbf{I}$. They cannot be observed in the data and their infinite 
series are not available. As every VMA process has a VAR representation, they can be extracted from the residuals $e_{i, t}$ of

$$
\hat{\mathbf{y}}_{i}, t=\mathbf{\Psi} \hat{\mathbf{y}}_{i, t-1}+e_{i, t}
$$

which is a $\operatorname{VAR}(1)$ process. For this purpose we must find $\boldsymbol{\Phi}_{i, 0}$, as

$$
\boldsymbol{\Phi}_{i, 0}^{-1} e_{i, t}=\sigma_{i, t}
$$

transforms the reduced form shocks of the $\operatorname{VAR}(1)$ into the genuine shocks of the $\operatorname{VMA}(\infty)$ process. The steps leading to equation (15) and the decomposition procedure needed to extract $\boldsymbol{\Phi}_{i, 0}$ from the VAR is described in detail in the appendix. ${ }^{3}$ It is shown there, that the underlying Choleski decomposition requires a restriction to be imposed on the matrix of longrun multipliers, which follows directly from equations (12) and (13). According to the identification scheme in the previous section we assume that $\sum_{\ell=0}^{\infty} \boldsymbol{\Phi}_{i, \ell}(1,2)=0$. This is equivalent to say that the assumed unit root in the productivity growth series is not influenced permanently by demand shocks, or in other words, demand shocks do not have a permanent influence on technical change on the sectoral level, even though they are an important driving force of structural change. This is in line with the model in section two and much of the literature on technical change discussed in the previous section. It has been shown by Francis and Ramey [12] that his identification scheme performs very well in extracting technology shocks from the data. Hall-Evans tests carried out on our shocks reported below support this view also for the sectoral context.

\section{The data}

The data are yearly data for Austrian manufacturing and cover the period 1971-1995. Due to changes in industry classification comparable data is not available for later years. The labour productivity series is from the ISIS database of Statistics Austria. The labour productivity is an index of real production per hour worked. The index of worked hours are derived from the labour productivity and the real production value also taken from the ISIS database (Appendix B.1 provides the details of the derivation of the series). Sectoral employment data, price cost margins, deflated industry sales were all taken from the Industrial Statistics of Statistics Austria. The data for firm dynamics did cover only the period between 1980-1994 and were derived from the membership statistics of the Austrian Chambers of Commerce. Hölzl [18] provides a detailed discussion of this data. The macroeconomic indicator of hours worked was obtained from Biffl's [3]. GDP, the GDP deflator, government expenditures and quasi money were taken from the

\footnotetext{
${ }^{3}$ For an exhaustive treatment see Amisano and Giannini [1, chapter 6] or Hamilton [16, p.324ff.].
} 
International Financial Statistics (IMF). Appendix B provides more details on the data.

\section{Results}

\subsection{Sector specific technology and demand shocks}

The identification of shocks In order to identify the technology and demand shocks in the different industrial sectors of the Austrian economy, we have estimated a $\operatorname{VAR}(1)$ for each sector $i$ and extracted the shocks from its residuals through structural factorization. Augmented Dickey-Fuller and KPSS tests were carried out on the series of log productivity and log hours including an intercept and a time trend. They showed that the unit root characterization for these series is a good description of the underlying stochastic process. ${ }^{4}$ The modulus of the VAR(1) matrix $\boldsymbol{\Psi}_{i}$ was less than 1 for each of the VARs estimated, indicating that the they were stable and covariance stationary, so that the $\operatorname{VMA}(\infty)$ representation exists. The estimation was also done for macro-data in order to have economy-wide shocks, which could be compared with our sectoral results. The VAR residuals were used to extract the technology and demand shocks according to equation (15) following the procedure outlined in appendix A.

Impulse responses Figure (1) shows the estimated impulse-responses based of the logs in productivity and hours to a one standard deviation innovation for each industry. ${ }^{5}$ For almost all sectors the productivity growth rate experiences an immediate increase in response to a positive technology shock, while the hours growth rate decreases for almost all sectors. This provides evidence for the theoretical model underlying our empirical analysis. Increases in the productivity growth rate have a negative impact on hour, which reduces the base for employment in the different sectors. This can only be compensated by positive demand shocks or a high degree of labour mobility, as conjectured by Pasinetti. The two sectors where hours respond adversely to the model are foundries and machinery and appliances, with the effect being somewhat more accentuated in the latter. A possible explanation is that demand in these sectors is very price elastic and (national or international) competition is very intense, so that productivity gains translate into falling prices which induce a proportionally higher demand leading

\footnotetext{
${ }^{4}$ The lag selection for the ADF tests was based on the Schwarz Information Criterion, and the KPSS test was based on GLS detrended residuals and an autoregressive spectral density estimator at frequency zero. The details are given in an appendix which can be obtained from the authors upon request.

${ }^{5}$ As discussed by Amisano and Giannini [1, chapter 6] asymptotic standard errors for the structural impulse response functions are not available for long-run models, therefore confidence bands were obtained by bootstrapping the data.
} 
to an increase in hours. This is not implausible for these partly integrated sectors. What is also apparent is that some declining sectors such as the mining or the leather producing sectors and processing industries such as the petroleum industry, basic metal products, stone and ceramic or glass and glass product manufacturing respond much stronger than other sectors to technology shocks with a permanent reduction in hours. For the first batch this may indicate that technology shocks are mostly induced by firm exits, while for the latter batch it captures much of the international competitive pressure lasting on the firms operating in these sectors. Most of them are able to survive in a high cost environment like the Austrian Economy (as compared to less developed countries) only through productivity growth and the reduction of employment.

The responses of log productivity to demand shocks are zero out of the restriction imposed in the structural VAR. Positive demand innovations have a positive and lasting impact on the growth of worked hours in each sector, which is again very much in line with the theoretical model in section 2 . Again the responses are also slightly more accentuated for most of the industries with strong response to technology shocks.

Hall-Evans tests Hall [15] and Evans [10] claim that technology shocks as computed by Solow are correlated with other exogenous shocks that are not related to technology. We will therefore examine if the measures of shocks that were derived here pass the Hall and Evans tests. The tests look whether the shocks isolated are correlated with other exogenous disturbances that are not related to technology. In order to do this, we regress technology and demand shocks on a constant and log per capita government spending, log GDP deflator and log per capita nominal money. We test whether these variables Granger-cause the technology and the demand shock.

(Table 1 about here)

Table 1 reports the tests for each of the industries. The results show that the regression identified technology innovations. We take this as evidence that the identified technology shocks are a measure of true technological development.

\subsection{Principal components in technology and demand shocks}

Principal components analysis (PCA) is a multivariate statistic technique which transforms a set of $k$ indicators on $l$ statistical units into a reduced set of variables explaining a significant proportion of the variability of the 
original set of data. Formally, this corresponds to a recursive maximization problem, where for the $i$ th recursion we have

$$
\begin{aligned}
\max \mathbf{c}_{i}^{\prime} \mathbf{c}_{i}= & \mathbf{b}_{i}^{\prime} \mathbf{X}^{\prime} \mathbf{X} \mathbf{b}_{i} \\
\text { s.t. } & \mathbf{b}_{i}^{\prime} \mathbf{b}_{i}=1, \\
& \mathbf{b}_{i}^{\prime} \mathbf{b}_{j}=0, \quad i \neq j,
\end{aligned}
$$

so that after $n$ recursions we get

$$
\begin{aligned}
\mathbf{c} & =\mathbf{X B} \\
\text { and } \mathbf{B}^{\prime} \mathbf{B} & =\mathbf{I},
\end{aligned}
$$

where $n$ corresponds to the number of shock series, i.e. the number of sectors. The vectors $\mathbf{b}_{i}$ are the orthonormal vectors transforming the matrix of extracted shocks $\mathbf{X}$ into main components $\mathbf{c}_{i}$. Each component explains variation $\mathbf{c}_{i}^{\prime} \mathbf{c}_{i}$ with the total variation in the data given by $\sum_{i} \mathbf{c}_{i}^{\prime} \mathbf{c}_{i}$. Matrix $\mathbf{I}$ is the identity matrix.

Each component explains the highest possible variance in the shock matrix $\mathbf{X}$ given the variance extracted by a previous component. The components obtained trough PCA are uncorrelated, linear combinations of the original variables with unit variance. It is easy to show that this procedure is equivalent to an extraction of eigenvectors from the correlation matrix of the data, where the eigenvectors with the largest eigenvalues also explain the largest part of the observed variance in the data. It is our purpose here to find out how the identified technology shocks in each industry contribute to the total observed variance throughout all industrial sectors, or vice versa, which shocks are best explained by which components. For this purpose we have calculated the squared correlation between each component and a sectoral shock indicating the proportion of variation in $x_{i}$ explained by component $c_{j}$. This measure is of particular interest for our analysis, as it allows a componentwise explanation of the shocks.

Technology shocks The results for the PCA on technology shocks are summarised in table 2 . It is evident that the heterogeneity in the data is very high. The first principal component accounts for only $21,69 \%$ of the total variance across industries. Industries seem not to synchronize in technological development lending support to Harberger's "mushrooms" evidence for US industries (see Harberger [17]). It is good evidence for ongoing structural change and an unbalanced development in labour productivity. For thirteen out of nineteen industries the first component is among the components explaining the largest part in their variance ranging from eighteen to sixty percent. Even though this component explains a large part of the variance in most industries it does not explain any variance in the observed macroeconomic technology shock. This would seem to indicate at first that macroeconomic conditions affecting nationwide productivity do not correlate with 
one major factor affecting the productivity development in almost all manufacturing sectors. Yet, closer inspection shows that components $c_{2}$ and $c_{3}$ do account for some major part in variance in the macro shock and together they explain about $25 \%$ of the variance in technology shocks across all industries. These components reflect the contrast between high and low growth industries. So macroeconomic technology conditions seem to correlate with sectoral developments in manufacturing, but still their correlation is not too strong, indicating that macroeconomic factors influencing technological development are not as important - at leas in Austria - as sectoral innovation systems (see Malerba [22]) or completely idiosyncratic developments in each industry. This is apparent in component $c_{5}$ which accounts for a large part in variance in integrated sectors like paper production and paper processing or leather production and leather processing. Components $c_{7}$ through $c_{11}$ seem to capture completely industry specific developments in productivity. The other story this evidence tells is that macro shocks in labour productivity are probably more closely related to other non-manufacturing sectors in the Austrian economy than to manufacturing industries.

Demand shocks The results for the PCA on demand shocks are displayed in table (3). They are quite different from the evidence on technology shocks. Almost all industries (except mining, petroleum and leather processing) share one principal component $c_{1}$, which accounts for $45.16 \%$ of the total variance across industries and between thirty and eighty percent of the variance in the demand shocks in each industry. Furthermore this component explains also a large part of the variance observed in the macroeconomic demand shocks. This is a strong indication that sectoral fluctuations in demand are correlated to macroeconomic fluctuations. This is the main difference from the PCA analysis of technology shocks, where the heterogeneity in the data was much higher. General macroeconomic demand expansion affects all sectors, but some industries decline while others grow. This is a possible interpretation for components $c_{2}, c_{3}$, and $c_{4}$. Component $c_{2}$ seems to reflect a contrasting development between some less competitive intermediate industries (related to basic good production) and the consumer goods sector on the one hand and competitive intermediate good industries and the capital good sector on other hand. This results from a closer inspection of the industries characteristics. It captures some part of a peculiarity in Austrian manufacturing industries, where the export intensive intermediate good and capital goods sector is internationally very competitive while the basic goods and consumer goods industries are declining or struggling. Hence, component $c_{2}$ captures the openess of sectors. Looking at the eigenvector of component $c_{2}$ (not reported here) its values indicate a contrast between industries engaged in the production of inferior and superior goods, but table (3) shows that this component explains much variance only in the 
petroleum and the leather processing industries. Component $c_{3}$ is related to $c_{2}$ and captures part of sectoral decline due to macro-shocks to demand. Most other components seem to be either idiosyncratic to some groups of industries (e.g. $c_{6}$ to basic goods sector) or to single industries. Overall, given the difficulties of interpretation, the evidence suggests that the explanation of innovations in demand given in the previous section is plausible.

\subsection{The impact of technology and demand shocks on Austrian manufacturing industries}

The model by Pasinetti [30] from which the SVAR identification scheme was deduced presents clear cut predictions for employment dynamics. Technology shocks should be correlated negatively with employment growth, demand shocks positively. We want to go further than testing this direct hypothesis. Exploring the impact of technology and demand shocks on other important variables on the industry level provides the basis for the interpretation and the nature of the shocks we isolated.

We study with the help of simple regression analysis hypotheses regarding the impact of technology shocks on important variables such as employment, sales and entry and exit dynamics. We use the fixed effect effect estimator in order to allow for heterogenous intercepts and to reduce the risk of biased estimates. In order to check the possible heterogeneity of results we run the fixed effect regressions also for subgroups of industries, as the behavior to an demand or technology shock may be differ across the broader industry groupings. In the intermediates industry group we isolated the effect of the petroleum industry, as this industry has a much higher concentration ratio than the other industries, and is influenced in a more direct way by the oil price shocks.

The impact on employment growth From the discussion on the theory it should be clear that we expect a negative correlation between technology shocks and employment growth and a positive correlation between demand shocks and employment growth.

(Table 4 about here)

Table 4 presents the regression results. As expected we find a negative relationship between technology shocks and the growth rate of employment in the industry and a positive relationship between demand shocks and employment growth. Also the lagged demand shocks and technology shocks show the expected sign, albeit they are not statistically significant. The $r^{2}$ is high, that means industry-specific technology and demand shocks are important determinants of employment dynamics at the industry level. This 
result is interesting as it shows that while the shocks - especially the technology shocks - are quite heterogenous between the industries that the reaction to the shocks is uniform across the industries. The separate regressions for the capital goods, intermediate goods and consumer goods sectors in table 4 confirm the result that there is a nearly uniform response in terms of employment to technology and demand shocks. We conclude that employment dynamics are guided to a large extent by technology and demand shocks in the way conjectured by Pasinetti.

The impact on the growth of gross production value. As it can be argued that the result as regards employment growth is due to our identification scheme, let us now consider the growth of production. True demand shocks should be correlated with the growth rate of production. For technology shocks no prediction can be given. Technology shocks may or may not influence the growth of production value. Only in very exceptional cases a technology shock should lead to an immediate response of demand. Therefore we expect that technology shocks are less correlated with the growth rate of the gross production value than demand shocks.

\section{(Table 5 about here)}

Table 5 presents the regression results for the growth rate of sales. Demand shocks are as expected uniformly positive and highly correlated with the growth rate of production. Interestingly, the correlation between demand shocks and the growth rate of the gross production value is highest for the capital goods industries but very strong also for the intermediate and the consumer goods industries. Technology shocks show a more differentiated picture. The correlation is significant and positive for capital goods industries but significant and negative for the intermediate goods industries. For intermediate goods industries without the petroleum industry the coefficient is still negative but statistically insignificant. For consumer goods industries technology shocks seem not to be correlated with the growth rate of production. This suggests that technology shocks lead to heterogeneous responses across the industries. Overall, the regression confirms that the demand shocks we identified are true demand shocks, and that technology shocks lead to heterogeneous responses across industries.

The impact on the growth of price-cost margins Let us now turn to a more controversial issue, the impact of our identified shocks on price cost margins. Price cost margins are used in industrial economics as measures of profitability. They are defined as value added from industrial activity minus expenditures for wages and salaries over turnover. The growth 
rate of price-cost margins is a measure that makes price-cost margins more comparable across industries. Price-cost margins do not reflect adequately the level of profitability, as capital R\&D and advertising expenditures are not accounted for.

The relationship between price-cost margins (PCM) and concentration is an important aspect in empirical industrial organization. Domowitz et al. [8] found that the degree response of price-cost margins on increases in industry demand depends positively on the concentration of an industry. This leads us to suspect that depending on the specific market structure in the industry demand shocks should have a positive impact on price cost margins. On the other hand Bloch and Olive [5] found that the relationship between demand and price-cost margins is negative for highly concentrated industries. We do not want to enter into this discussion, but note that the results obtained so far, indicate that our demand shocks are expected to interact with structural features of industrial competition. Therefore we included an indicator of PCM for small firms, which we define as firms with less than 50 employees. We expect that while overall PCM might not be significant, small firm PCM should reveal the impact of the shocks in regard to the competitive balance between small and large firms.

\section{(Table 6 about here)}

Table 6 provides the estimation results. PCM for all firms is not explained by demand and technology shocks. Only for capital goods industries the lagged demand shock is significant at the ten percent level. Overall, the changes in price cost margins are not well described by neither demand nor technology shocks. Industry specific OLS regressions (not reported) show that the heterogeneity is very high. In some sectors demand shocks influence in a positive way the growth of PCM, for other industries the relationship is negative. Interestingly however, demand shocks and technology shocks are able to explain much more the changes in PCM for small firms (less than 50 employees), but the response is heterogeneous. For capital goods industries, demand shocks correlate positively with PCM and the coefficient on lagged technology shocks is negative. For intermediate goods industries we obtain an opposing result: lagged demand shocks reduce the PCM of small firms, while technology shocks increase them. The PCM of consumer goods industries seem not to be influenced in a systematic way by demand and technology shocks. This result calls for further research in its own to explain the determinants of the heterogeneity of the response of PCM across industries to demand and technology shocks. 
The impact on entry, exit and net entry The entry and exit of firms is an important determinant of the structural change within industries. Net entry measures the change in stock of firms. Entry, exit and net entry are measured as rates relative to the number of firms active in the industry in the previous year. Technological change is at the root of the theory of industrial evolution and entry, exit and net entry are central variables explaining the development of industries (e.g.Nelson and Winter [21], Winter [36], Jovanovic and McDonald [19], Klepper [20]). Demand is relevant as it defines market size and determines the room for firms. Therefore, demand is expected to be correlated in positive way with entry and net entry and in a negative way with exit.

Table 7 displays the results from the fixed effect regression. They show that the technology and demand shocks are not able to explain the firm dynamics in terms of entry, exit and net entry of firms in terms of the explained variance measured by $r^{2}$. The demand shocks have as expected a positive correlation to entry and net entry and a negative with exit. However, only the first two are statistically significant for all firms. Technology shocks are significant only lagged for net entry with a negative sign. The regressions for the different industry groups are in the appendix (see table 8). The results show that our technology and demand shocks are unable to explain firm dynamics in the consumer goods sector. The results for capital goods sectors and intermediate goods sectors are more promising. However the reaction to demand shocks is relatively heterogeneous across the industry groupings. Also the technology shocks show no clear patterns. Technology shocks reduce entry in the capital goods sector while they increase entry in the intermediate goods sector.

(Table 7 about here)

This result suggests that the demand and technology shocks we have identified primarily explain employment dynamics but not entry and exit dynamics. The reason for this is that our technology shocks identify permanent changes in labour productivity but they do not indicate the nature of technological change. As Winter [36] suggested there might be different technological regimes. One which favors incumbents as the knowledge base of the innovative process is cumulative and another one which favors new firms, as the relevant knowledge base for innovation is largely external to the industry. The knowledge base of an industry is an important determinant of market structure of an industry. An introspection of the OLS results for single industries (not reported) shows that the intercept is in all industries highly significant and heterogenous. This indicates that entry and exit are determined to a large extend by the structural characteristics of an industry, 
as confirmed also by a large number of empirical studies. Hölzl [18] shows that sunk costs are an important element governing entry and exit dynamics in Austrian Manufacturing. In regard to firm dynamics the interaction between shocks and the structural features of industrial competition needs to be explored more in detail. The patterns of specialization and macroeconomic performance are determined by these structural features. And indeed, the Austrian industry is characterized by a pronounced lack of specialization in technology driven industries (e.g. Peneder [31], Tichy [35]).

\section{Discussion and conclusion}

We find that the theoretical model underlying our analysis of structural dynamics is well supported by the data. The identified sectoral technology and demand shocks were shown to be genuine in so far as they do not to correlate with other exogenous macroeconomic disturbances. The impulse-response analysis for each sector shows a common pattern across industries that employment (proxied by hours worked) permanently and negatively responds to positive technology shocks, while positive demand shocks positively affect the growth of employment in each sector. This confirms Pasinetti's conjecture that sectoral employment patterns are negatively correlated with productivity growth and positively correlated with demand expansion.

The principal components analysis used to identify common components in variance in the extracted shocks delivered a number of interesting results. As expected heterogeneity in technology shocks is much higher than in demand shocks. The first principal component for demand shocks explains a much higher part of total variance than it is the case for technology shocks. The sectoral demand shocks share also their first principal component with the macroeconomic demand shock, indicating that the sectoral demand shocks are strongly correlated with macroeconomic demand conditions. This would support the idea of "sorting". The macroeconomic "technology shock" has no common first component with all industries. There is only a weak correlation between macro-economic developments in productivity and technical change in manufacturing industries, suggesting that the development of labour productivity follows a "mushroom" pattern, while the development of demand is much more homogeneous. This lends support to the idea that selection and related productivity development is mostly an industry specific phenomenon, while sorting depends much more on the general pattern of income development.

The structural dynamics express themselves in the sectoral evolution of employment, sales and market structure. We tested how well the identified innovations in technology and demand could explain these parameters. The identified technology and demand shock were strongly correlated to the growth rate of employment and sales, as expected from the theory. Surpris- 
ingly, they did not explain at all the entry and exit dynamics, indicating that the determinants of market structure are not immediately related to short run changes in technology and demand. While the heterogeneity of shocks between sectors is very high as established, their response in employment and sales was identical, so that it came as a surprise that this was not the case for the firm dynamics. This suggests that they are more likely to depend on the specific structural and institutional characteristics in each industry.

Acknowledgements: This research project was supported by a research grant (project nr. 9800) of the Jubiläumsfond der Österreichische Nationalbank (OeNB). 


\section{A The extraction of technology and de- mand shocks from the VAR residuals}

As the $\operatorname{VMA}(\infty)$ process in equation (14) contains non-observable technology and non-technology shock parameters, it is necessary to rewrite it as an VAR(1) process (omitting the subscript $i$ identifying each sector) of the form

$$
\begin{aligned}
\hat{\mathbf{y}}_{t} & =\boldsymbol{\Psi} \hat{\mathbf{y}}_{t-1}+e_{t}=\boldsymbol{\Psi} L \hat{\mathbf{y}}_{t}+e_{t} \\
& =(\mathbf{I}-\boldsymbol{\Psi} L)^{-1} e_{t} .
\end{aligned}
$$

Here the $e_{t}$ 's are the reduced form shocks. They are linear combinations of technology and non-technology (demand) shocks $\sigma_{d t}$ and $\sigma_{s t}$ in equation (14). The inverse $(\mathbf{I}-\mathbf{\Psi} L)^{-1}$ represents the estimated accumulated responses to the observed shocks, as $(\mathbf{I}-\mathbf{\Psi} L)^{-1} \approx \mathbf{I}+\boldsymbol{\Psi} L+(\boldsymbol{\Psi} L)^{2}+\ldots+(\boldsymbol{\Psi} L)^{n}$, with $n \rightarrow \infty .^{6}$ Taking out the lag operator we can rewrite equation (16) as:

$$
\hat{\mathbf{y}}_{t}=\mathbf{I} e_{t}+\mathbf{\Psi} e_{t-1}+\mathbf{\Psi}^{2} e_{t-2}+\ldots+\mathbf{\Psi}^{n} e_{t-n} .
$$

Comparing the first terms in equations (14) and (17) we get by definition $\mathbf{I} e_{t}=\boldsymbol{\Phi}_{0} \sigma_{t}$, which leads to equation (15). It gives us the shocks from the residuals of the VAR.

The multiplier matrix $\boldsymbol{\Phi}_{0}$ is extracted from the $\operatorname{VAR}(1)$ matrix $\boldsymbol{\Psi}$ through the following decomposition. Due to the orthonormality imposed on the shocks $\sigma_{s_{t}}$ and $\sigma_{d_{t}}$ it must be that

$$
\operatorname{Cov}\left(\mathrm{ee}^{\prime}\right)=\boldsymbol{\Phi}_{0} \boldsymbol{\Phi}_{0}^{\prime}=\boldsymbol{\Sigma} .
$$

Comparing equations (14) and (17) and by recalling equation (15) we can say that

$$
\boldsymbol{\Phi}_{1} \mathrm{~L} \sigma_{t}=\boldsymbol{\Psi} \mathrm{L} e_{t} \rightarrow \boldsymbol{\Phi}_{1} \mathrm{~L} \sigma_{t}=\boldsymbol{\Psi} \boldsymbol{\Phi}_{0} \mathrm{~L} \sigma_{t} \rightarrow \boldsymbol{\Psi}=\boldsymbol{\Phi}_{1} \boldsymbol{\Phi}_{0}^{-1}
$$

and in general for any lag

$$
\Psi^{\ell}=\boldsymbol{\Phi}_{\ell} \boldsymbol{\Phi}_{0}^{-1}
$$

Finally, the resulting equation taking account of all lags is

$$
\sum_{\ell=0}^{\infty} \boldsymbol{\Psi}^{\ell}=\sum_{\ell=0}^{\infty} \boldsymbol{\Phi}_{\ell} \boldsymbol{\Phi}_{0}^{-1} .
$$

For easier handling we may introduce the following definitions:

$$
\sum_{\ell=0}^{\infty} \Psi^{\ell}=[\mathbf{I}-\mathbf{\Psi}]^{-1}:=\mathbf{R}(1) \quad \text { and } \quad \sum_{\ell=0}^{\infty} \boldsymbol{\Phi}_{\ell}:=\mathbf{C}(1) .
$$

Taking equation (19) we write

$$
\mathbf{R}(1)=\mathbf{C}(1) \boldsymbol{\Phi}_{0}^{-1}
$$

${ }^{6}$ The matrix $(\mathbf{I}-\mathbf{\Psi} L)$ is of course non-singular, i.e. $(\mathbf{I}-\mathbf{\Psi} L)(\mathbf{I}-\mathbf{\Psi} L)^{-1}=\mathbf{I}$ 


$$
\mathbf{C}(1)=\mathbf{R}(1) \Phi_{0} .
$$

As $\mathbf{R}(1)$ and $\boldsymbol{\Sigma}$ from equation (18) are known, it is possible to find $\mathbf{C}(1)$ by post-multiplying the left part of (20) with its inverse

$$
\mathbf{R}(1) \boldsymbol{\Phi}_{0} \boldsymbol{\Phi}_{0}^{\prime} \mathbf{R}(1)^{\prime}=\mathbf{R}(1) \boldsymbol{\Sigma} \mathbf{R}(1)^{\prime}=\mathbf{C}(1) \mathbf{C}(1)^{\prime} .
$$

Due to the restriction that non-technology shocks do not affect long run productivity growth, $\sum_{\ell=0}^{\infty} \boldsymbol{\Phi}_{\ell}(1,2)=\mathbf{C}(1)_{12}=0$ we can carry out a lower triangular Choleski decomposition to get $\mathbf{C}(1)$. By plugging this result back into equation (20) and finding the solution to $\mathbf{R}(1)^{-1} \mathbf{C}(1)$, the matrix of long run multipliers of the exogenous shocks $\boldsymbol{\Phi}_{0}$ results. The multiplication of the inverse of this matrix with the series of residuals from the estimation of (16) as shown in equation (15) gives then the series of technology and nontechnology shocks. The factorization procedure described in this appendix is implemented in the Eviews and STATA packages, which we used both to derive our results.

\section{B Data appendix}

Table 9 lists the industries used in the empirical research. Industries 8 and 9, film industry and sawmills were excluded due to incomplete data. Table 11 lists variables and their sources.

\section{(Tables 9, 10 and 11 about here)}

\section{B.1 The extraction of working hours}

Statistik Austria does not provide data on hours worked for the industries. However they provide an index of productivity per hour worked. From this index an index of hours worked can be obtained with the help of the index of physical production. As real labour productivity per hour is defined as $\alpha=\frac{Y}{H}$, where $Y$ is real output and $H$ is total hours, total hours can be obtained by $H=\frac{Y}{\alpha}$, where $Y$ is now the index of production. In a similar fashion also hours per worker can be obtained.

\section{B.2 Industry specific deflators}

As the Austrian statistical office does not provide data on real production values or specific output-deflators, the index of physical production and nominal production values were used to calculate the desired industry-specific deflators. The current value of production for the quantity produced in 1995 for each year was calculated by multiplying the nominal production with the 
index of production $(100=1995)$. Then industry-specific output-deflators are obtained by dividing the current value of the quantity produced in 1995 by the nominal production value in 1995 . 


\section{References}

[1] Amisano G. and C. Giannini (1997), Topics in Structural VAR Econometrics, Heidelberg: Springer.

[2] Andersen, E.S. (2001), Satiation in an Evolutionary Model of Structural Economic Dynamics, Journal of Evolutionary Economics, vol.11, 143-64.

[3] Biffl, Gudrun (2000), Die Entwicklung des Arbeitsvolumens und der Arbeitsproduktivität nach Branchen, Vienna: WIFO Working Paper 136/2000.

[4] Blanchard, O. and Danny Quah (1989), The Dynamic Effects of Aggregate Demand and Supply Disturbances, in: American Economic Review, vol. 79, 655-673.

[5] Bloch, Harry and Michael Olive (2001), Pricing over the Cycle, Review of Industrial Organization, vol. 19, 99-108.

[6] Burnside, A. C., M. S. Eichenbaum, and S. T. Rebelo (1996), Sectoral Solow Residuals, European Economic Review, vol.40, 861-869.

[7] Carlaw K.I. and R. Lipsey (2003), Productivity, technology and economic growth: what is the relationship? Journal of Economic Surveys, vol.17, 457-495.

[8] Domowitz, Ian, R.Glenn Hubbard and Bruce C. Petersen (1986) Business Cycles and the Relationship between Concentration and Price-Cost Margins, Rand Journal of Economics, vol. 17, $1-17$.

[9] Dosi G. (1997), Opportunities, Incentives and the Collective Patterns of Technological Change, Economic Journal, vol. 107, 1530-1547.

[10] Evans, Charles L. (1992), Productivity shocks and real business cycles, Journal of Monetary Economics, vol. 29, 191-208.

[11] Felipe J. and Franklin M. Fisher (2003), Aggregation in production functions: what applied economists should know, Metroeconomica, vol.54, 208-262.

[12] Francis, N., and V. A. Ramey (2002), Is the Technology-Driven Real Business Cycle Hypothesis Dead? Shocks and Aggregate Fluctuations Revisited, Cambridge Mass.: NBER Workingpaper 8726.

[13] Galí, J. (1999), Technology, Employment, and the Business Cycle: Do Technology Shocks Explain Aggregate Fluctuations?, American Economic Review, vol. 89, 249-271.

[14] Galí J. (2004), On the role of technology shocks as a source of business cycles: some new evidence, Journal of the European Economic Association, 2, 372-380.

[15] Hall, Robert E. (1988), The relation between price and marginal cost in U.S. industry, Journal of Political Economy, vol. 96, 921-947. 
[16] Hamilton, J.D. (1994), Time Series Analysis, Princeton: Princeton University Press

[17] Harberger, A. C. (1998), A Vision of the Growth Process, American Economic Review, vol.88, 1-32.

[18] Hölzl, Werner (2003), Tangible and Intangible Sunk Costs an the Entry and Exit of Firms in Austrian Manufacturing, Vienna: Vienna University of Economics and Business Administration, Working Paper in Growth and Employment in Europe: Sustainability and Competitiveness No. 33.

[19] Jovanovic, B. and MacDonald, G.M. (1994) The Life Cycle of a Competitive Industry, Journal of Political Economy, vol. 102, 562-583.

[20] Klepper, Steven (2002), Firm Survival and the Evolution of Oligopoly, Rand Journal of Economics, vol. 33, 37-61.

[21] Nelson, R., and S. Winter (1982), An Evolutionary Theory of Economic Change. Boston: Belknap, Harvard University Press.

[22] Malerba, F. (2002), Sectoral Systems of Innovation and Production, Research Policy, vol.31, 247-264.

[23] Mansfield, E. (1985), How rapidly does new industrial technology leak out?, Journal of Industrial Economics, vol. 34, 217223.

[24] Metcalfe, J.S. (1998), Evolutionary Economics and Creative Destruction, London: Routledge

[25] Metcalfe, J.S., J. Foster and R. Ramlogan (2002), Adaptive Economic Growth, Manchester: CRIC Discussion Paper No.59.

[26] Mokyr, J. (1985), Demand vs. Supply in Industrial Revolution, in The Economics of Industrial Revolution, ed. by J. Mokry: Rowman and Littlefield Publ., 97-118.

[27] Montobbio, F. (2002), An evolutionary model of industrial growth and structural change, Structural Change and Economic Dynamics, vol. 13, 387-414.

[28] Mowery D.C. and Rosenberg, N. (1979), The influence of market demand upon innovation: a critical review of some recent empirical studies ,Research Policy, vol.8, 102-153

[29] Pasinetti, Luigi L. (1981), Structural Change and Economic Growth, Cambridge: Cambridge University Press.

[30] Pasinetti, Luigi L. (1993), Structural economic dynamics, Cambridge: Cambridge University Press

[31] Peneder, Michael (1999), The Austrian Paradox: Old Structures but High Performance, Austrian Economic Quarterly, vol.4, 239-247.

[32] Peneder, Michael (2003), Industrial structure and aggregate growth, Structural Change and Economic Dynamics, vol.14, 427-448. 
[33] Schmookler, J. (1966), Invention and Economic Growth. Harvard: Harvard University Press.

[34] Sraffa, P. (1926), The laws of return under competitive conditions, Economic Journal, vol. 36, 535-50

[35] Tichy, G. (2000), The Innovation Potential and Thematic Leadership of Austrian Industries: An Interpretation of the Technology Delphi with Regard to the Old Structures High Performance Paradox, Empirica, vol. 27, 411-436.

[36] Winter, S. G. (1984), Schumpeterian Competition in Alternative Technological Regimes, in Journal of Economic Behavior and Organization, vol.5, 287-320 
Tables and Figures

Table 1: Hall-Evans-test

\begin{tabular}{|r|rrr|rrr|}
\hline & technology & shocks & & demand & shocks & \\
\hline & $r^{2}$ & $F$-test & Prob $>F$ & $r^{2}$ & $F$-test & Prob $>F$ \\
\hline 2 & 0.04 & 0.27 & 0.85 & 0.13 & 0.95 & 0.44 \\
3 & 0.06 & 0.40 & 0.75 & 0.09 & 0.62 & 0.61 \\
4 & 0.17 & 1.33 & 0.29 & 0.05 & 0.31 & 0.81 \\
5 & 0.20 & 1.57 & 0.23 & 0.06 & 0.40 & 0.76 \\
6 & 0.13 & 0.92 & 0.45 & 0.04 & 0.27 & 0.85 \\
7 & 0.05 & 0.34 & 0.80 & 0.11 & 0.78 & 0.52 \\
10 & 0.23 & 1.91 & 0.16 & 0.25 & 2.15 & 0.13 \\
11 & 0.16 & 1.18 & 0.35 & 0.03 & 0.21 & 0.89 \\
12 & 0.20 & 1.54 & 0.24 & 0.33 & 3.07 & 0.05 \\
13 & 0.19 & 1.50 & 0.25 & 0.24 & 2.00 & 0.15 \\
14 & 0.04 & 0.23 & 0.87 & 0.17 & 1.26 & 0.32 \\
15 & 0.11 & 0.77 & 0.52 & 0.06 & 0.37 & 0.77 \\
16 & 0.06 & 0.41 & 0.75 & 0.04 & 0.30 & 0.83 \\
17 & 0.11 & 0.77 & 0.52 & 0.04 & 0.28 & 0.84 \\
18 & 0.10 & 0.69 & 0.57 & 0.07 & 0.50 & 0.69 \\
19 & 0.16 & 1.21 & 0.33 & 0.03 & 0.16 & 0.92 \\
20 & 0.05 & 0.31 & 0.82 & 0.03 & 0.22 & 0.88 \\
21 & 0.12 & 0.88 & 0.47 & 0.09 & 0.63 & 0.60 \\
$M S$ & 0.17 & 1.32 & 0.30 & 0.04 & 0.28 & 0.84 \\
& 0.11 & 0.78 & 0.52 & 0.11 & 0.78 & 0.52 \\
\hline
\end{tabular}


Table 2: Proportion of variance accounted for by component $c_{i}$ in sectoral technology shocks (TS) by principal component (squared correlation $\left[r\left(c_{i}, \sigma_{i}\right)\right]^{2}$ ). Sectors and macro-shock. Legend: (EV) eigenvalue, (ExV) explained Variance, (Cum) cumulated ExV, (Prop.Var) Proportion of variance explained by bold marked components, numbers in first column give the industry IDs, MS the macro shock.

\begin{tabular}{|c|c|c|c|c|c|c|c|c|c|c|c|c|c|}
\hline & $c_{1}$ & $c_{2}$ & $c_{3}$ & $c_{4}$ & $c_{5}$ & $c_{6}$ & $c_{7}$ & $c_{8}$ & $c_{9}$ & $c_{10}$ & $c_{11}$ & $c_{12}$ & Prop. Var. \\
\hline EV & 4.34 & 3.32 & 1.88 & 1.84 & 1.41 & 1.30 & 1.10 & 1.01 & 0.88 & 0.82 & 0.58 & 0.52 & \\
\hline ExV & $21.69 \%$ & $16.60 \%$ & $9.39 \%$ & $9.18 \%$ & $7.04 \%$ & $6.51 \%$ & $5.50 \%$ & $5.04 \%$ & $4.39 \%$ & $4.12 \%$ & $2.91 \%$ & $2.58 \%$ & \\
\hline Cum & $21.69 \%$ & $38.29 \%$ & $47.68 \%$ & $56.86 \%$ & $63.90 \%$ & $70.41 \%$ & $75.91 \%$ & $80.95 \%$ & $85.34 \%$ & $89.46 \%$ & $92.37 \%$ & $94.95 \%$ & \\
\hline 1 & 0.0917 & 0.0260 & 0.1987 & 0.1802 & 0.0000 & 0.1100 & 0.0366 & 0.0688 & 0.0326 & 0.0108 & 0.2135 & 0.0185 & 0.7023 \\
\hline 2 & 0.0084 & 0.0103 & 0.3114 & 0.4003 & 0.0182 & 0.0141 & 0.0226 & 0.0023 & 0.0491 & 0.0423 & 0.0012 & 0.0361 & 0.7118 \\
\hline 3 & 0.4263 & 0.0957 & 0.0466 & 0.0600 & 0.0307 & 0.0004 & 0.1982 & 0.0012 & 0.0573 & 0.0147 & 0.0014 & 0.0197 & 0.6245 \\
\hline 4 & 0.3964 & 0.0363 & 0.1108 & 0.0322 & 0.0604 & 0.1234 & 0.0196 & 0.0399 & 0.0605 & 0.0109 & 0.0030 & 0.0127 & 0.6305 \\
\hline 5 & 0.0639 & 0.4330 & 0.1985 & 0.0505 & 0.0099 & 0.0054 & 0.0613 & 0.0007 & 0.0664 & 0.0220 & 0.0364 & 0.0128 & 0.6315 \\
\hline 6 & 0.2353 & 0.0111 & 0.0364 & 0.2595 & 0.2286 & 0.0453 & 0.0000 & 0.0000 & 0.0941 & 0.0077 & 0.0303 & 0.0164 & 0.7234 \\
\hline 7 & 0.0560 & 0.0105 & 0.3143 & 0.2591 & 0.1432 & 0.0739 & 0.0182 & 0.0337 & 0.0260 & 0.0006 & 0.0008 & 0.0053 & 0.7166 \\
\hline 10 & 0.3143 & 0.0224 & 0.0050 & 0.0151 & 0.0031 & 0.0408 & 0.0038 & 0.0641 & 0.0043 & 0.4936 & 0.0000 & 0.0151 & 0.8079 \\
\hline 11 & 0.3533 & 0.1757 & 0.0725 & 0.1031 & 0.0085 & 0.1089 & 0.0196 & 0.0342 & 0.0049 & 0.0057 & 0.0241 & 0.0083 & 0.7410 \\
\hline 12 & 0.3440 & 0.1553 & 0.1008 & 0.0310 & 0.1763 & 0.0259 & 0.0572 & 0.0209 & 0.0266 & 0.0006 & 0.0088 & 0.0055 & 0.7764 \\
\hline 13 & 0.2032 & 0.2905 & 0.0041 & 0.0022 & 0.2425 & 0.0044 & 0.0192 & 0.0490 & 0.0525 & 0.0008 & 0.0443 & 0.0308 & 0.7362 \\
\hline 14 & 0.0150 & 0.4984 & 0.0120 & 0.0057 & 0.0357 & 0.0721 & 0.1137 & 0.0319 & 0.0915 & 0.0026 & 0.0010 & 0.0687 & 0.7036 \\
\hline 15 & 0.0481 & 0.2662 & 0.0003 & 0.0409 & 0.0433 & 0.0634 & 0.0560 & 0.3440 & 0.0151 & 0.0120 & 0.0386 & 0.0368 & 0.6103 \\
\hline 16 & 0.1837 & 0.2239 & 0.0203 & 0.0028 & 0.0067 & 0.1564 & 0.2189 & 0.0050 & 0.0875 & 0.0073 & 0.0129 & 0.0382 & 0.6103 \\
\hline 17 & 0.0001 & 0.2778 & 0.1315 & 0.2053 & 0.0028 & 0.0656 & 0.1510 & 0.0158 & 0.0018 & 0.0023 & 0.0889 & 0.0112 & 0.7828 \\
\hline 18 & 0.2249 & 0.3147 & 0.0130 & 0.0574 & 0.2403 & 0.0048 & 0.0393 & 0.0030 & 0.0001 & 0.0379 & 0.0024 & 0.0171 & 0.7799 \\
\hline 19 & 0.2909 & 0.0282 & 0.1346 & 0.1074 & 0.0833 & 0.2189 & 0.0385 & 0.0007 & 0.0275 & 0.0057 & 0.0003 & 0.0061 & 0.7518 \\
\hline 20 & 0.6045 & 0.0418 & 0.0010 & 0.0226 & 0.0548 & 0.0890 & 0.0061 & 0.0002 & 0.0344 & 0.0425 & 0.0002 & 0.0178 & 0.6935 \\
\hline 21 & 0.4658 & 0.0980 & 0.0159 & 0.0000 & 0.0082 & 0.0480 & 0.0020 & 0.0022 & 0.1195 & 0.0603 & 0.0692 & 0.0556 & 0.6833 \\
\hline MS & 0.0114 & 0.3046 & 0.1504 & 0.0009 & 0.0109 & 0.0316 & 0.0192 & 0.2896 & 0.0268 & 0.0429 & 0.0052 & 0.0822 & 0.7446 \\
\hline
\end{tabular}


Table 3: Proportion of variance accounted for by component $c_{i}$ in sectoral demand shocks (DS) by principal component. Sectors and macro-shock

\begin{tabular}{|c|c|c|c|c|c|c|c|c|c|c|c|c|}
\hline & $c_{1}$ & $c_{2}$ & $c_{3}$ & $c_{4}$ & $c_{5}$ & $c_{6}$ & $c_{7}$ & $c_{8}$ & $c_{9}$ & $c_{10}$ & $c_{11}$ & Prop. Var. \\
\hline $\mathrm{EV}$ & 9.03 & 2.31 & 1.45 & 1.26 & 1.14 & 1.03 & 0.77 & 0.71 & 0.62 & 0.45 & 0.37 & \\
\hline ExV & $45.16 \%$ & $11.57 \%$ & $7.25 \%$ & $6.29 \%$ & $5.68 \%$ & $5.16 \%$ & $3.83 \%$ & $3.57 \%$ & $3.09 \%$ & $2.25 \%$ & $1.84 \%$ & \\
\hline Cum & $45.16 \%$ & $56.73 \%$ & $63.98 \%$ & $70.27 \%$ & $75.95 \%$ & $81.11 \%$ & $84.93 \%$ & $88.50 \%$ & $91.59 \%$ & $93.84 \%$ & $95.67 \%$ & \\
\hline 1 & 0.0843 & 0.5938 & 0.0204 & 0.0172 & 0.0317 & 0.1019 & 0.0041 & 0.0225 & 0.0087 & 0.0745 & 0.0064 & 0.6957 \\
\hline 2 & 0.0052 & 0.2900 & 0.4251 & 0.0025 & 0.0803 & 0.0422 & 0.0472 & 0.0102 & 0.0025 & 0.0513 & 0.0350 & 0.7151 \\
\hline 3 & 0.4274 & 0.2006 & 0.0174 & 0.0320 & 0.0771 & 0.0125 & 0.0328 & 0.0730 & 0.0003 & 0.0394 & 0.0154 & 0.6280 \\
\hline 4 & 0.6952 & 0.0064 & 0.0047 & 0.0055 & 0.0686 & 0.0265 & 0.0031 & 0.0539 & 0.0006 & 0.0004 & 0.0145 & 0.6952 \\
\hline 5 & 0.6951 & 0.0146 & 0.0325 & 0.0322 & 0.0242 & 0.0151 & 0.0313 & 0.0164 & 0.0880 & 0.0072 & 0.0066 & 0.6951 \\
\hline 6 & 0.5550 & 0.1401 & 0.0303 & 0.0000 & 0.0007 & 0.0007 & 0.0850 & 0.0034 & 0.0603 & 0.0079 & 0.0565 & 0.6951 \\
\hline 7 & 0.5713 & 0.0304 & 0.0277 & 0.1271 & 0.0361 & 0.1077 & 0.0163 & 0.0007 & 0.0034 & 0.0023 & 0.0368 & 0.8061 \\
\hline 10 & 0.4663 & 0.0113 & 0.0019 & 0.0005 & 0.0250 & 0.3214 & 0.0036 & 0.0781 & 0.0491 & 0.0158 & 0.0019 & 0.7877 \\
\hline 11 & 0.4937 & 0.0546 & 0.0035 & 0.1236 & 0.1226 & 0.0634 & 0.0609 & 0.0029 & 0.0016 & 0.0005 & 0.0275 & 0.7400 \\
\hline 12 & 0.1076 & 0.1384 & 0.0916 & 0.1757 & 0.0089 & 0.1453 & 0.0165 & 0.2590 & 0.0001 & 0.0148 & 0.0125 & 0.8260 \\
\hline 13 & 0.0080 & 0.3029 & 0.4119 & 0.0064 & 0.0229 & 0.0221 & 0.0868 & 0.0628 & 0.0131 & 0.0330 & 0.0101 & 0.7148 \\
\hline 14 & 0.3675 & 0.1489 & 0.0213 & 0.1542 & 0.0505 & 0.0947 & 0.0084 & 0.0004 & 0.0274 & 0.0465 & 0.0466 & 0.6706 \\
\hline 15 & 0.4565 & 0.0156 & 0.0245 & 0.3216 & 0.0483 & 0.0069 & 0.0162 & 0.0553 & 0.0020 & 0.0054 & 0.0031 & 0.7781 \\
\hline 16 & 0.5524 & 0.0064 & 0.0009 & 0.0222 & 0.1389 & 0.0293 & 0.0575 & 0.0402 & 0.0085 & 0.0944 & 0.0125 & 0.6913 \\
\hline 17 & 0.5562 & 0.0014 & 0.0520 & 0.0406 & 0.0929 & 0.0050 & 0.0483 & 0.0049 & 0.1153 & 0.0269 & 0.0045 & 0.6715 \\
\hline 18 & 0.8080 & 0.0517 & 0.0022 & 0.0102 & 0.0350 & 0.0005 & 0.0527 & 0.0001 & 0.0037 & 0.0045 & 0.0033 & 0.8080 \\
\hline 19 & 0.6516 & 0.0076 & 0.0008 & 0.0509 & 0.0313 & 0.0296 & 0.0004 & 0.0002 & 0.0965 & 0.0108 & 0.0573 & 0.7480 \\
\hline 20 & 0.8472 & 0.0149 & 0.0524 & 0.0006 & 0.0028 & 0.0005 & 0.0000 & 0.0068 & 0.0149 & 0.0025 & 0.0000 & 0.8472 \\
\hline 21 & 0.3268 & 0.2721 & 0.0230 & 0.1216 & 0.0268 & 0.0061 & 0.1680 & 0.0140 & 0.0180 & 0.0086 & 0.0000 & 0.8886 \\
\hline MS & 0.3566 & 0.0122 & 0.2053 & 0.0131 & 0.2114 & 0.0006 & 0.0266 & 0.0084 & 0.1035 & 0.0034 & 0.0168 & 0.7733 \\
\hline
\end{tabular}


Table 4: Employment growth and technology shocks and demand shocks

\begin{tabular}{lccccc}
\hline & all & 1 & 2 & 2 & 3 \\
\hline DS & 0.022 & 0.02 & 0.02 & 0.025 & 0.025 \\
& {$[14.17]^{* * *}$} & {$[8.06]^{* * *}$} & {$[10.51]^{* * *}$} & {$[6.07]^{* * *}$} & {$[7.23]^{* * *}$} \\
DS lag & 0.016 & 0.017 & 0.011 & 0.006 & 0.018 \\
& {$[10.31]^{* * *}$} & {$[6.79]^{* * *}$} & {$[5.80]^{* * *}$} & {$[1.44]$} & {$[5.35]^{* * *}$} \\
TS & -0.013 & -0.01 & -0.012 & -0.011 & -0.018 \\
& {$[8.55]^{* * *}$} & {$[3.86]^{* * *}$} & {$[6.02]^{* * *}$} & {$[2.93]^{* * *}$} & {$[5.22]^{* * *}$} \\
TS lag & -0.002 & 0 & -0.004 & -0.003 & -0.003 \\
& {$[1.62]$} & {$[0.19]$} & {$[2.27]^{* *}$} & {$[0.82]$} & {$[0.96]$} \\
\hline Observations & 399 & 126 & 126 & 70 & 126 \\
Number of id & 19 & 6 & 6 & 5 & 6 \\
R-squared & 0.50 & 0.50 & 0.62 & 0.42 & 0.49 \\
\hline
\end{tabular}

Notes: Absolute value of $\mathrm{t}$ statistics in brackets; * significant at $10 \% ; * *$ significant at $5 \%$; *** significant at $1 \%$; industry specific intercepts not reported.

1 denotes the capital goods sector, 2 the intermediate goods sector, 2' the intermediate goods sector without petroleum industry and 3 the consumer goods sector.

Table 5: The growth of gross production value and technology shocks and demand shocks

\begin{tabular}{lccccc} 
& all & 1 & 2 & 2 & 3 \\
\hline DS & 0.04 & 0.06 & 0.023 & 0.028 & 0.029 \\
& {$[14.24]^{* * *}$} & {$[14.32]^{* * *}$} & {$[4.45]^{* * *}$} & {$[4.86]^{* * *}$} & {$[6.48]^{* * *}$} \\
lag DS & 0 & 0.002 & -0.004 & -0.006 & 0.003 \\
& {$[0.06]$} & {$[0.40]$} & {$[0.82]$} & {$[1.12]$} & {$[0.79]$} \\
TS & 0.001 & 0.019 & -0.011 & -0.008 & -0.001 \\
& {$[0.36]$} & {$[4.32]^{* * *}$} & {$[2.06]^{* *}$} & {$[1.42]$} & {$[0.33]$} \\
lag TS & 0.002 & 0.006 & 0.002 & 0 & 0.006 \\
& {$[0.75]$} & {$[1.51]$} & {$[0.34]$} & {$[0.09]$} & {$[1.40]$} \\
\hline Observations & 399 & 126 & 126 & 105 & 126 \\
Number of id & 19 & 6 & 6 & 5 & 6 \\
R-squared & 0.35 & 0.66 & 0.18 & 0.22 & 0.28 \\
\hline
\end{tabular}

Notes: Absolute value of t statistics in brackets; * significant at $10 \% ; * *$ significant at $5 \%$; *** significant at

$1 \%$; industry specific intercepts not reported. petroleum industry and 3 the consumer goods sector. 


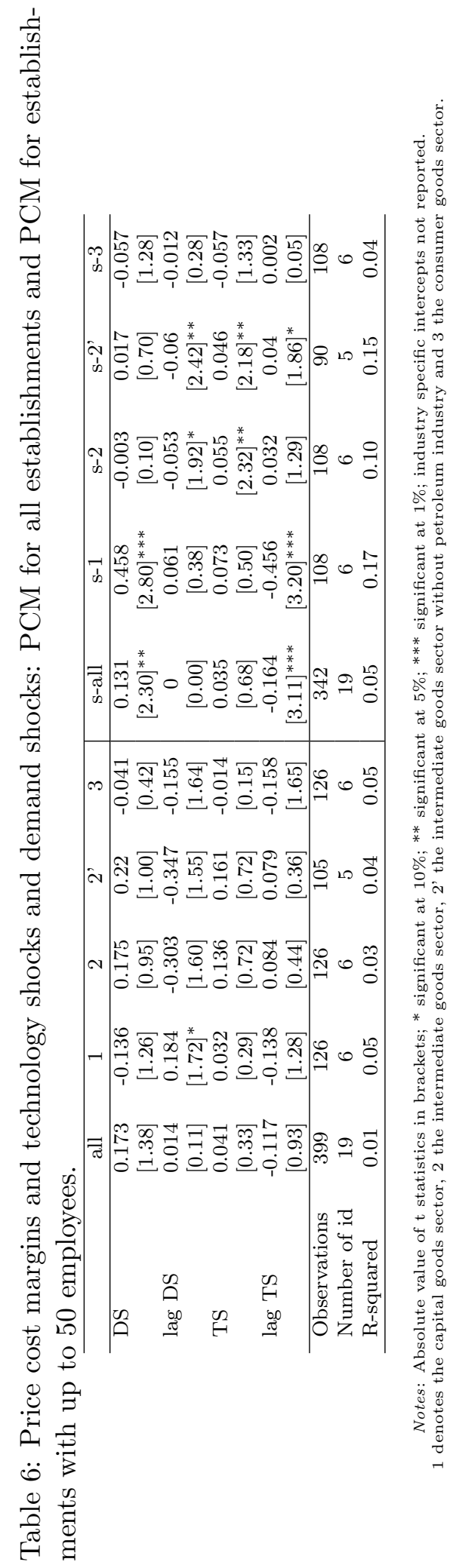


Table 7: Entry, exit and net entry and technology and demand shocks

\begin{tabular}{lccc}
\hline & entry & exit & net entry \\
\hline DS & 0.004 & -0.002 & 0.006 \\
& {$[1.99]^{* *}$} & {$[0.60]$} & {$[2.83]^{* * *}$} \\
TS & 0 & -0.001 & 0.001 \\
& {$[0.01]$} & {$[0.34]$} & {$[0.49]$} \\
ds1 & 0.002 & -0.002 & 0.003 \\
& {$[0.88]$} & {$[0.54]$} & {$[1.48]$} \\
ts1 & -0.001 & 0.003 & -0.005 \\
& {$[0.52]$} & {$[1.08]$} & {$[2.24]^{* *}$} \\
\hline Observations & 238 & 238 & 238 \\
Number of id & 17 & 17 & 17 \\
R-squared & 0.02 & 0.01 & 0.07
\end{tabular}

Notes: Absolute value of $\mathrm{t}$ statistics in brackets; ${ }^{*}$ significant at $10 \%$; ${ }^{* *}$ significant at $5 \%$; *** significant at $1 \%$; industry specific intercepts not reported. 


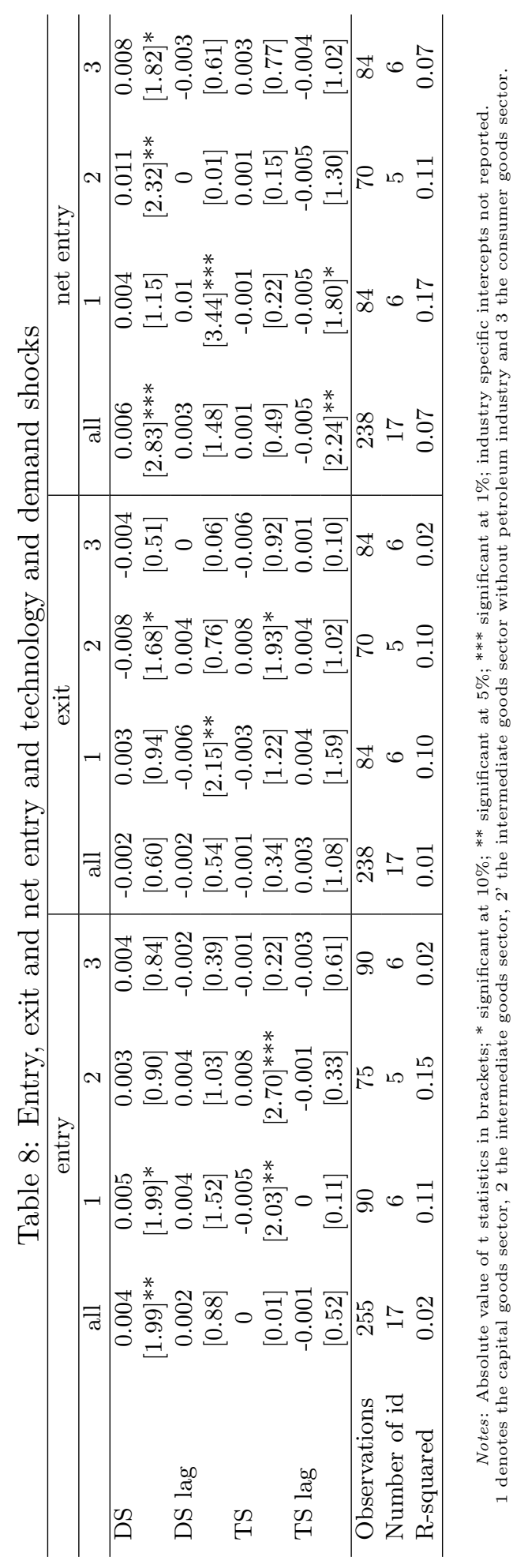


Table 9: List of industries

\begin{tabular}{lll}
\hline KS & Industry (German) & Industry (English) \\
\hline 1 & Bergwerke & mining \\
2 & Erdöl & oil and refinery \\
3 & Stein-Keramik & stone and ceramics \\
4 & Glas & chems and glass products \\
5 & Chemie & manufacture of pulp and paper \\
6 & Papiererzeugung & paper processing \\
7 & Papierverarbeitung & wood processing \\
10 & Holzverarbeitung & food and tobacco \\
11 & Nahrungs- und Genussmittel & leather producing \\
12 & Ledererzeugung & leather processing \\
13 & Lederverarbeitung & foundries \\
14 & Giesserei & metal industry except steel \\
15 & NE-Metall & machinery and steel constructions \\
16 & Maschinen-Stahlbau & transportation equipment \\
17 & KFZ & iron and metal products \\
18 & Eisen-Metal & electrical equipment, appliances and \\
19 & Elektroindustrie & components \\
& & textiles except clothing \\
20 & Textilindustrie & clothing \\
21 & Bekleidungsindustrie & \\
\hline
\end{tabular}

Table 10: Industry grouping

\begin{tabular}{lll}
\hline Code & Description & Industries (KS) \\
\hline 1 & capital goods industries & $14,15,16,17,18,19$ \\
2 & intermediate goods industries & $2,3,4,5,6,7$ \\
2 & intermediate goods industries without petroleum industry & $3,4,5,6,7$ \\
3 & consumer goods industries & $10,11,12,13,20,21$ \\
\hline
\end{tabular}

Table 11: Data sources

\begin{tabular}{lc}
\hline Variable & Source \\
\hline Labour productivity & sectoral \\
vouriables & ISIS Database (Statistik Austria) \\
Employment growth & derived as explained in B.1 \\
Sales growth & ISIS Database (Statistik Austria) \\
Price cost margins & ISIS Database (Statistik Austria) \\
Price cost margins small firms & ISIS Database (Statistik Austria) \\
Entry & ISIS Database (Statistik Austria) \\
& Membership statistics of the Austrian \\
Exit & Chamber of Commerce \\
& Membership statistics of the Austrian \\
Net Entry & Chamber of Commerce \\
& Membership statistics of the Austrian \\
Labour productivity & Chamber of Commerce \\
& derived from GDP and total hours \\
Total hours worked & worked \\
GDP & Biff [3] \\
Government expenditures & International Financial Statistics (IMF) \\
Quasimoney & International Financial Statistics (IMF) \\
& International Financial Statistics (IMF) \\
& International Financial Statistics (IMF) \\
\hline
\end{tabular}



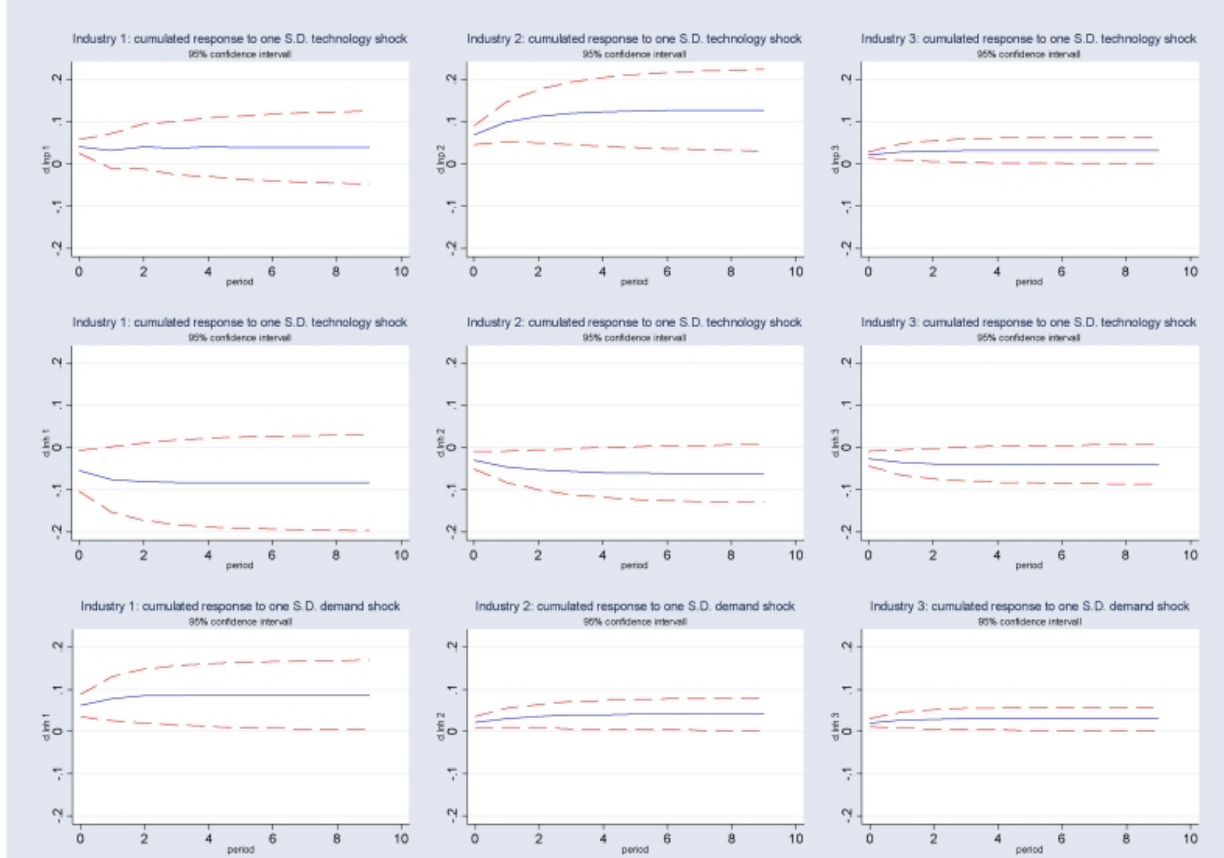

Figure 1: Impulse response functions for all industries with $5 \%$ confidence intervals obtained from bootstrapping. 


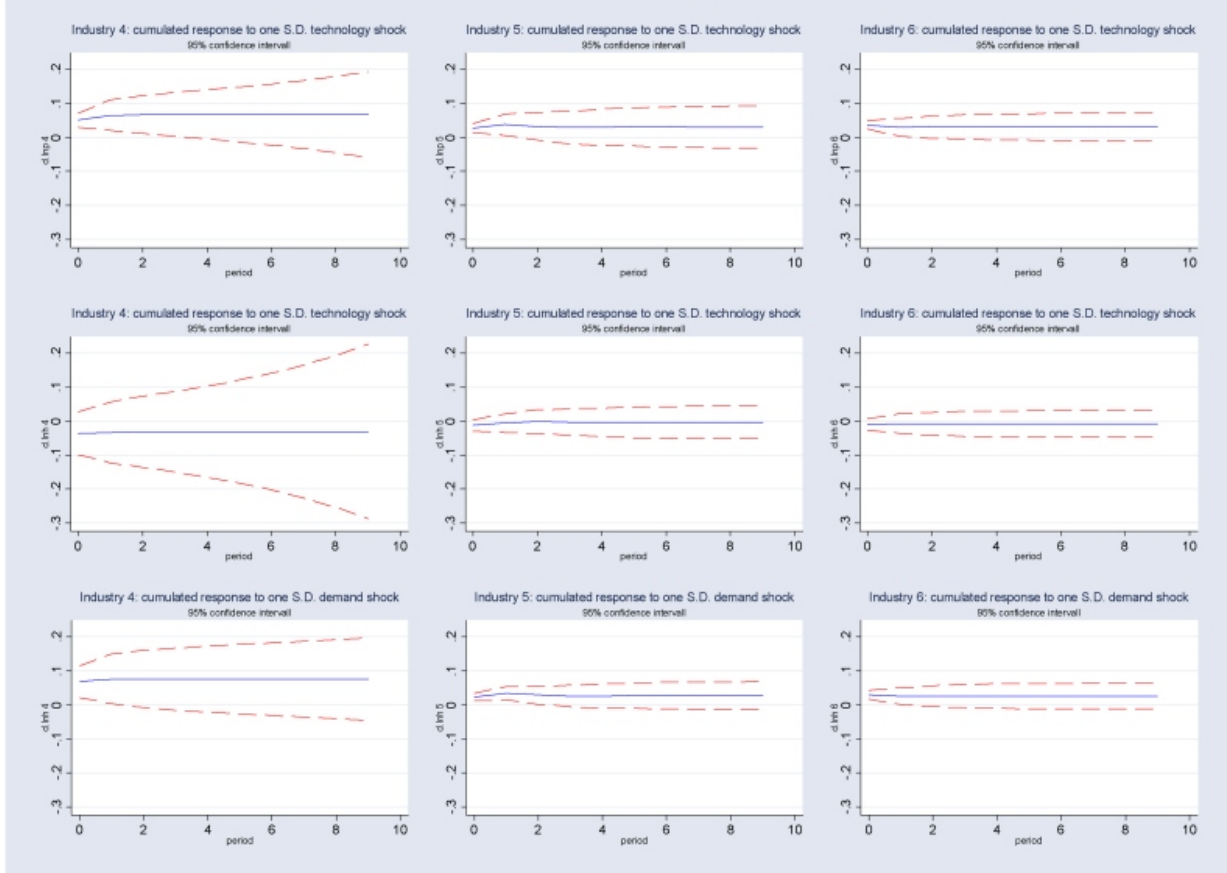




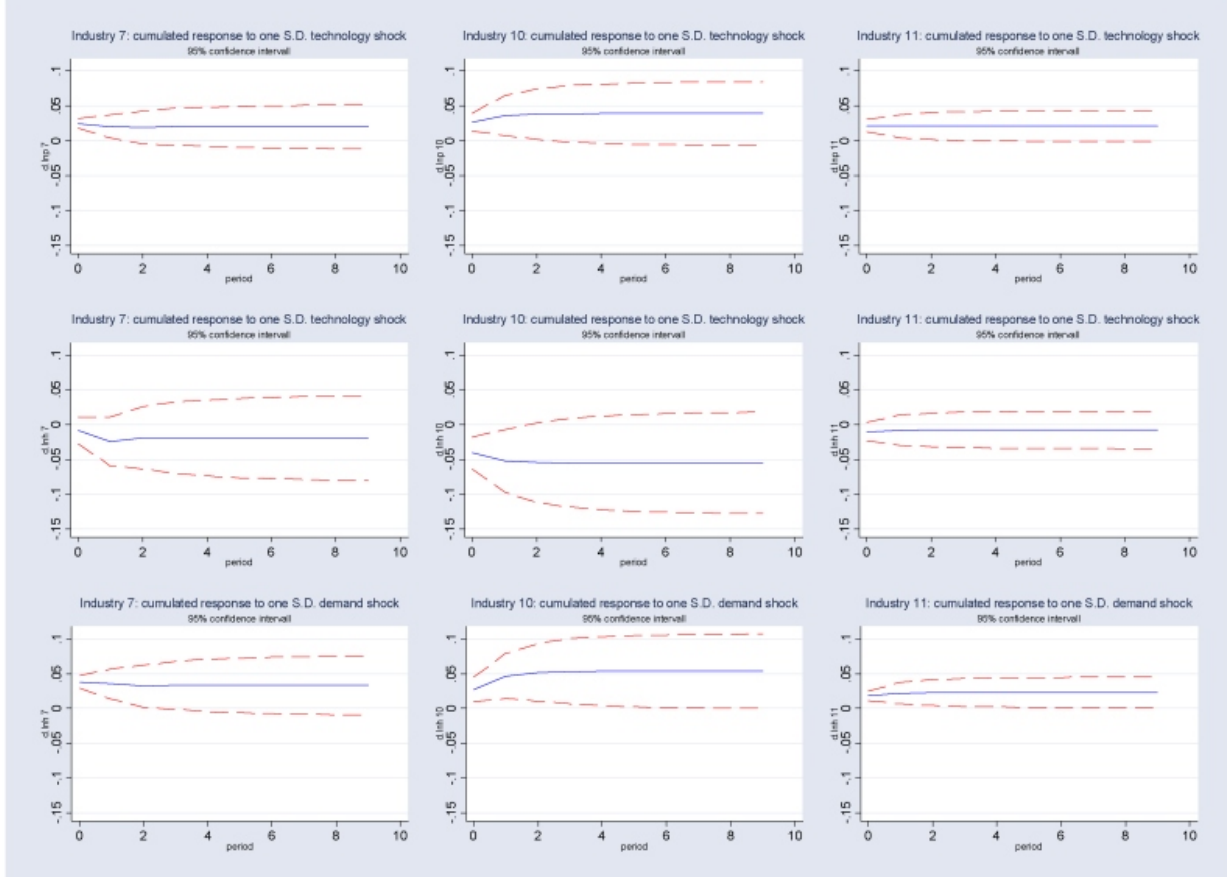




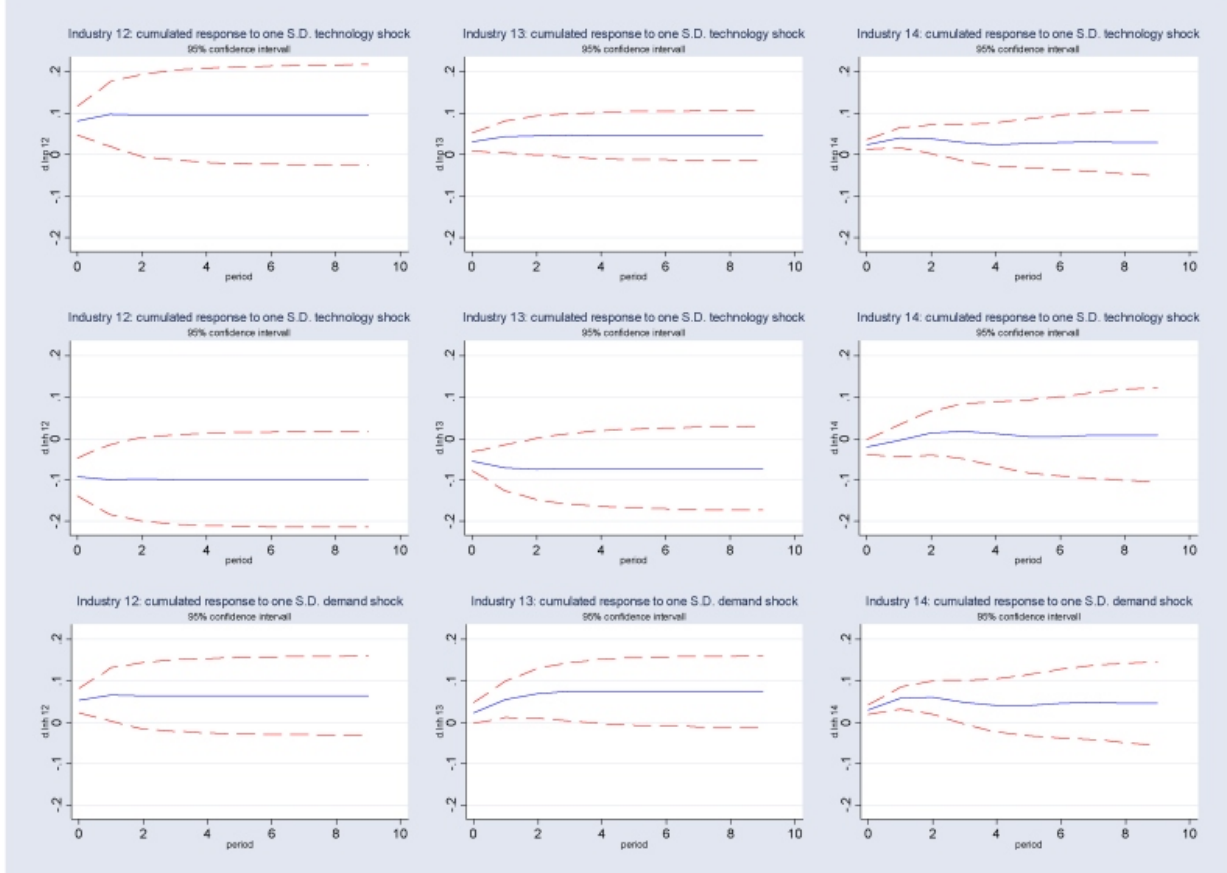




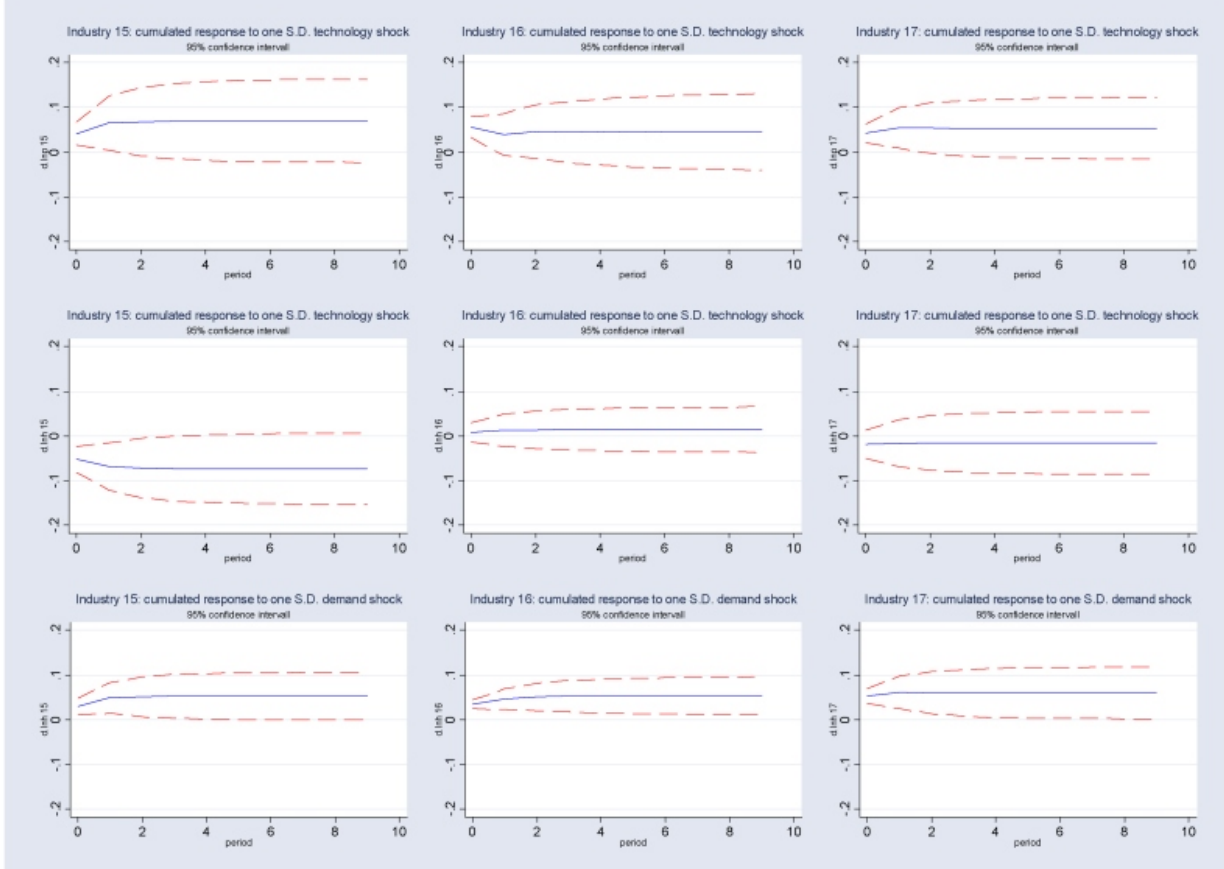




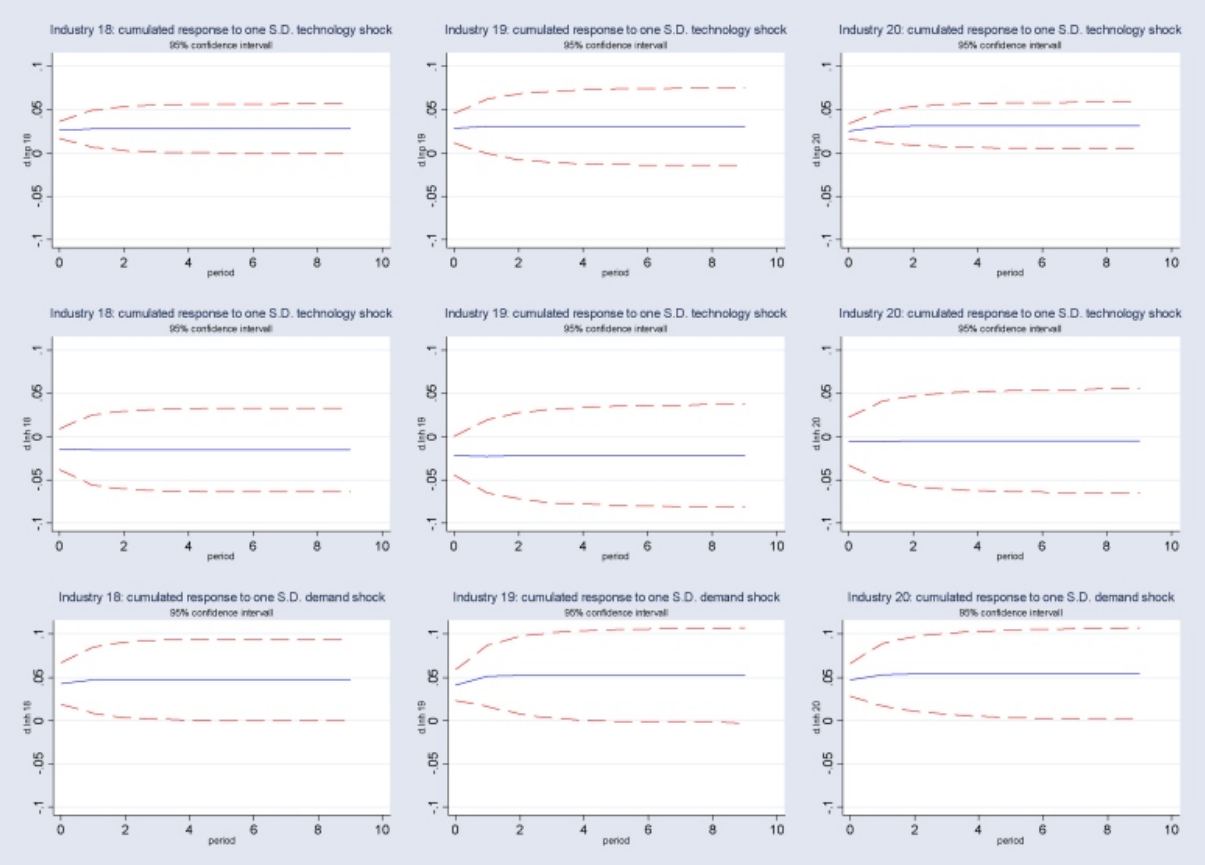




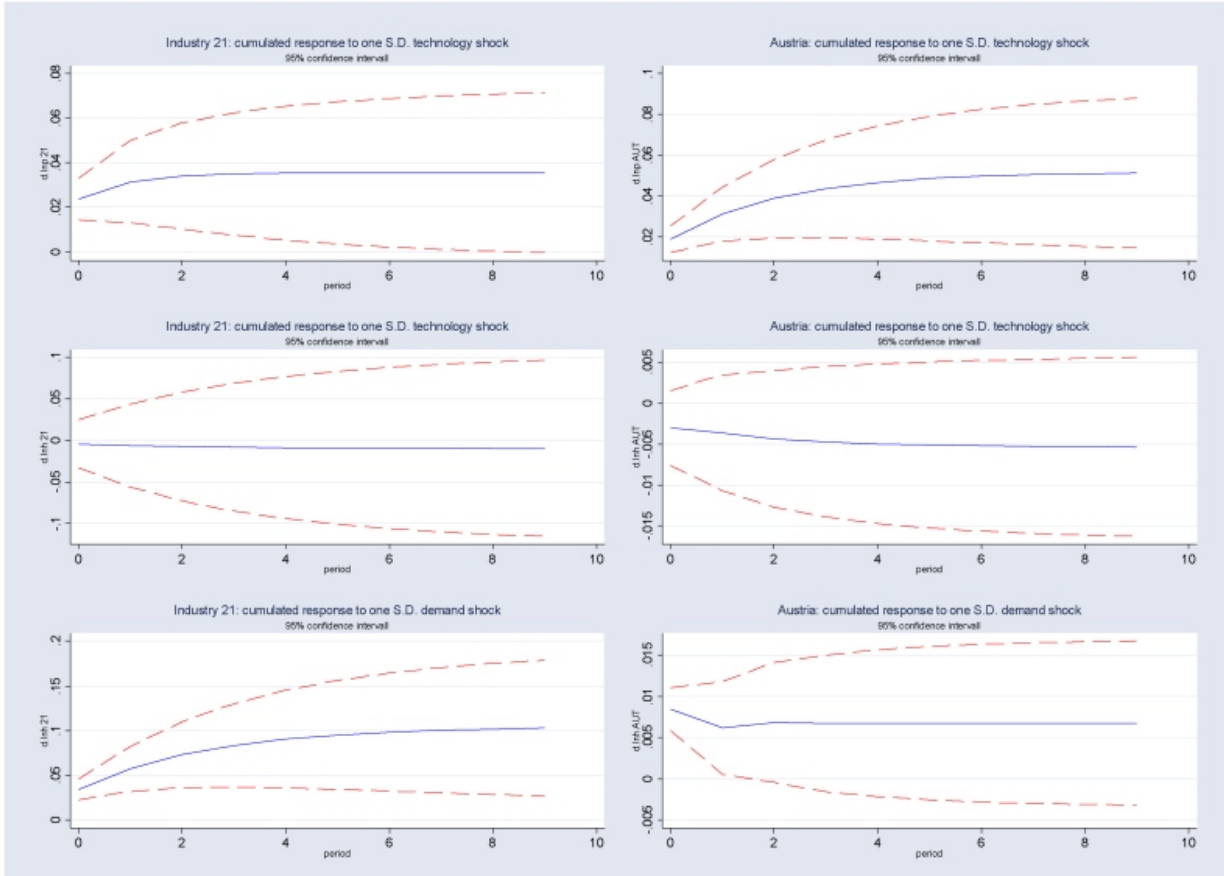

